CENTRE for ECONOMIC

$P$ E R F O R M A N C E

CEP Discussion Paper No 832

November 2007

\title{
Incentives in Competitive Search Equilibrium
}

Espen R. Moen and Åsa Rosén 


\begin{abstract}
This paper analyses the interaction between internal agency problems within firms and external search frictions when workers have private information. We show that the allocation of resources is determined by a modified Hosios Rule. We then analyze the effect of changes in the macro economic variables on the wage contract and the unemployment rate. We find that private information may increase the responsiveness of the unemployment rate to changes in productivity. The incentive power of the wage contracts is positively related to high productivity, low unemployment benefits and high search frictions.
\end{abstract}

Keywords: Private information, incentives, search, unemployment, wage rigidity JEL Classifications: E30, J30, J60

This paper was produced as part of the Centre’s Labour Markets Programme Programme. The Centre for Economic Performance is financed by the Economic and Social Research Council.

\title{
Acknowledgements
}

This is a revised version of an earlier paper entitled 'Incentives in Competitive Search Equilibrium and Wage Rigidity', 2006. We would like to thank Per Engstrom, Matthew Lindquist, Marta Lochowska, Robert Shimer, and seminar participants at Northwestern University, University of Pennsylvania, University of Chicago, University of Albany, Federal Reserve Bank of Richmond, ESSLE, Stockholm University, Göteborg University, Humboldt University in Berlin, University of Bonn, University of the Research Institute of Industrial Economics, and the Swedish Institute for Social Research for valuable comments. Financial support from the Norwegian Research Council and the Swedish Research Council are gratefully acknowledged.

Espen R. Moen is Professor of Economics at the Norwegian School of Management, Oslo, Norway. Åsa Rosén is Professor of Economics at the Swedish Institute for Social Research (SOFI), Stockholm University.

Published by

Centre for Economic Performance

London School of Economics and Political Science

Houghton Street

London WC2A 2AE

All rights reserved. No part of this publication may be reproduced, stored in a retrieval system or transmitted in any form or by any means without the prior permission in writing of the publisher nor be issued to the public or circulated in any form other than that in which it is published.

Requests for permission to reproduce any article or part of the Working Paper should be sent to the editor at the above address.

C E E. R. Moen and Å. Rosén, submitted 2007

ISBN 978-0-85328-207-5 


\section{Introduction}

There exists a large literature analyzing the effects of search frictions in the labor market. In this literature firms are typically modelled in a rather parsimonious way. In particular agency problems between workers and firms are ignored. The focus is thus solely on the effects of search frictions on the flows into and out of employment.

In this paper we dig deeper into the relationship between the worker and the firm. First, we introduce a moral hazard problem by letting a worker's work effort to be unobservable to the firm. Second, we assume that a worker also has private information regarding her productivity in that particular job. The firm acts as a principal and chooses a wage contract that maximizes profits given the information constraints. Our aim is to analyze the interplay between search frictions in the market place and agency problems created by private information within the firm.

Search frictions and agency problems interact because of the amount of "rents" that accrue to the worker. A worker's private information gives her an information rent, which is larger the closer wages are linked to the workers' output. When the firm sets the wage contract, it trades off incentives for the worker to provide effort and rent extraction from the worker. However, when there is search frictions in the labor market, more rents to the worker also benefits the firm as it speeds up the hiring process. Hence, it is less costly for a firm to provide workers with incentives when operating in a frictional market rather than in a frictionless market.

We show that the resulting search equilibrium, which we refer to as generalized competitive search equilibrium, has a simple form, and is characterized by a modified Hosios Rule that determines the constrained efficient resource allocation. When the information constraints are tight in a welldefined sense, the optimal wage contract leaves a relatively large amount of rents to the employees. As a result, profit will be lower, and fewer resources are used to create new jobs.

We then analyze the effects of changes in the macroeconomic environment on the wage contract and the unemployment rate. First we analyze the effects of negative productivity changes where all firms are hit equally hard. Such a negative shock tightens the constraints imposed by the workers' private information, and the worker's share of the match surplus increases. Therefore, the unemployment rate becomes more responsive to such shocks 
than in the standard search model. If the recession is caused by changes in the information structure, or if worker effort is more crucial after a negative change, the responsiveness of the unemployment rate to negative shocks is further increased and may be arbitrarily large.

Our model can thus contribute to the debate following Shimer (2005) and Hall (2004a) who document that fluctuations in the unemployment rate predicted by the model in response to observed productivity shocks are much smaller than actual fluctuations in the unemployment rate, as wages in the model absorb much of the shock. Note also that our analysis indicates that a counter-cyclical sharing rule, where workers receive a larger share of the surplus after a negative shock, may be an optimal response to information problems between employers and employees.

Furthermore, we find that a positive productivity shock or a fall in unemployment benefits both tend to increase the incentive power of the wage contract. In both cases the shift increases the average match surplus. As a result, there are more rents available in the relationship, and therefore also room for more high-powered incentive contracts. Similarly, an increase in search frictions also tends to increase the incentive power of the wage contract.

Our private information model builds on the procurement model by Laffont and Tirole (1993) and its adoption to a frictionless labor market by Moen and Rosén (2006). As the emphasis in the present paper is on the interplay between search frictions and wage contracts its analysis differs radically from that of Moen and Rosén (2006).

In a related model, Faig and Jerez (2005) analyze a retail market with search frictions when buyers have private information about their willingnessto-pay. Although their paper studies private information in a competitive search environment, their model and emphasis differ from ours. They focus on welfare analysis and abstract from moral hazard problems. Moreover, they neither derive the modified Hosios condition, nor analyze the impact of macroeconomic variables on sharing rules and incentives.

Shimer and Wright (2004) consider a competitive search model where firms (not workers) have private information about productivity and workers have private information about effort. They show how private information may distort trade, thereby increasing unemployment. However, the mechanism in their paper differs from ours. We focus on the division of the match surplus between workers and firms as an instrument to mitigate the inefficiencies caused by private information, summarized in the modified Hosios 
condition. This is absent in Shimer and Wright, who instead focus on the direct effect of the inefficiencies created by two-sided private information on unemployment and vacancy rates.

Several recent studies seek to make the search model consistent with Shimer and Hall's empirical findings. In Kennan (2004), workers and firms bargain over wages once they meet. Firms have private information in booms, but not in recessions, and thus earn information rents in booms. This increases the profits in booms, and thus also unemployment volatility. Nagypál (2004) and Krause and Lubik (2004) show that on-the-job search in a matching model may amplify the effects of productivity shocks on the unemployment rate. Menzio (2004) illustrates that firms with private information may find it optimal to keep wages fixed if hit by high-frequency shocks. In Rudanko (2005) the effect of risk averse workers and contractual incompleteness on volatility is explored. Reiter (2007) shows that the responsiveness of the unemployment may be increased if one allow for technological change that is embodied into the match. Gertler, Sala and Triari (2007) explain wage rigidity by among other things staggered wage contracts. For an extended survey of this literature see Mortensen and Nagypál (2006).

Our model is also related to the literature on efficiency wage models (e.g. Weiss, 1980; Shapiro and Stiglitz, 1984). Some of these papers examine the comparative static properties of efficiency wage models, (Strand, 1992; Danthine and Donaldson, 1990; Ramey and Watson, 1997; MacLeod, Malcomson and Gomme, 1994; MacLeod and Malcomson, 1998). In a static model, Rocheteau (2001) introduces shirking in a search model and shows that the non-shirking constraint forms a lower bound on wages.

The paper is organized as follows: Section 2 presents the model. The generalized competitive search equilibrium is defined in section 3 and characterized in section 4 . In section 5 we apply the model and analyze the effects of macroeconomic variables on the wage contract and the unemployment rate. Section 6 offers final comments.

\section{The model}

The matching of unemployed workers and vacancies is modelled using the Diamond-Mortensen-Pissarides framework (Diamond, 1982; Mortensen, 1986; Pissarides, 1985) with competitive wage setting. The economy consists of a 
continuum of ex ante identical workers and firms. All agents are risk neutral and have the same discount factor $r$. The measure of workers is normalized to one. Workers leave the market at an exogenous rate $s$ and new workers enter the market as unemployed at the same rate. Abandoned firms have no value.

We study a segment of the labor market where workers have the same observable characteristics. ${ }^{1}$ Still there is ex post heterogeneity. As in Jovanovic (1979) and many subsequent papers (See Pissarides 2000, ch. 6 for an overview) we assume stochastic job matching, meaning that the productivity of a given worker-firm pair is match-specific. In addition, output depends on worker effort. The output $y$ of a worker-firm pair is

$$
y(\varepsilon, e)=\bar{y}+\varepsilon+\gamma e,
$$

where $\bar{y}$ is a constant, $\varepsilon$ the match-specific term (or stochastic matching term), and $e$ worker effort. The parameter $\gamma$ is a measure of the relative importance of worker effort. As is common in the stochastic matching literature, we assume $\varepsilon$ is i.i.d across all worker-firm matches. (In footnote 5 we argue that our results also hold when allowing for some correlation of the stochastic match component.) For any given match, $\varepsilon$ is constant over time and continuously distributed on an interval $[\underline{\varepsilon}, \bar{\varepsilon}]$ with cumulative distribution function $H$, density function $h$, and with increasing hazard rate.

Output is observable to both the worker and the firm. However, as in most models of optimal wage contracts the worker (the agent) has an information advantage over the firm (the principal) - we assume that only the worker can decompose output $y$ into effort $e$ and the stochastic matching term $\varepsilon$.

As output is contractible, wage contracts are contingent on $y$. The utility flow of a worker is given by

$$
\omega=w-\psi(e)
$$

where $w$ denotes the wage (we suppress the functional dependence on $y$ ) and $\psi(e)$ the cost of effort. The function $\psi(e)$ is increasing, and its derivative $\psi^{\prime}(e)$ is increasing and convex in $e$. When a worker and a firm meet, the worker learns $\varepsilon$ and then decides whether to accept or reject the contract. As wages depend on $y$, a worker chooses her effort level such that $\frac{d w}{d y}=\psi^{\prime}(e)$.

\footnotetext{
${ }^{1}$ Workers with different observable (and contractible) characteristics would be offered different wage contracts. Furthermore, in competitive search equilibrium they search in separated search markets and hence do not create search externalities towards each other.
} 
For any given wage contract, there exists a cut-off value $\varepsilon_{c} \geq \underline{\varepsilon}$ such that a worker accepts a job if and only if $\varepsilon \geq \varepsilon_{c}$. If she rejects the contract she starts searching again, and the job remains vacant.

We know from the revelation principle that any output-dependent contract can be represented as a contract of the form $\phi=\left(w(\varepsilon), e(\varepsilon), \varepsilon_{c}\right)$, which satisfies the incentive compatibility constraint and the participation constraint of the worker, to be defined below. In what follows we define wage contracts on this form. We do not consider tenure-dependent contracts. This is without loss of generality, as we show later that the optimal contract is tenure-independent.

Let $u$ denote the unemployment rate and $v$ the vacancy rate in the economy. Firms are free to open vacancies at no cost, but maintaining a vacancy entails a flow cost $c$. The number of matches is determined by a concave, constant return to scale matching function $x(u, v)$. Let $p$ denote the matching rate of workers and $q$ the matching rate of firms. Since the matching function has constant return to scale, we can write $q=q(p)$, with $q^{\prime}(p)<0 .{ }^{2}$

Before we continue we want to make two comments regarding the set-up, both related to the match-specific term $\varepsilon$. The first comment regards the exact timing of when a worker learns the match specific productivity term $\varepsilon$. We assume that a worker learns $\varepsilon$ before the contract is signed. This sequence rules out up-front payments from the worker to the firm before the worker learns $\varepsilon$. If up-front payments are not admitted, it is sufficient that the worker learns $\varepsilon$ after exerting effort and observing $y$.

The second comment regards our assumption that the match-specific productivity term is unobservable to the firm. An alternative interpretation is that firms, although able to observe $\varepsilon$, are unwilling or unable to differentiate output-contingent wage contracts between workers with the same observable characteristics but with different stochastic matching terms. Different wage contracts would here mean offering less attractive contracts to workers with a high stochastic match term. Evidence that workers with different productivity work under the same bonus scheme is given in e.g., Lazear (2000).

Asset value equations

The asset value equations define the parties' payoffs for a given wage contract $\phi=\left(w(\varepsilon), e(\varepsilon), \varepsilon_{c}\right)$. Let $U$ denote the expected discounted utility of

\footnotetext{
${ }^{2}$ The probability rates $p$ and $q$ can be written as $p=x(u, v) / u=x(1, \theta)=\widetilde{p}(\theta)$ and $q=x(u, v) / v=x(1 / \theta, 1)=\tilde{q}(\theta)$. The matching technology can thus be summarized by a function $q=\tilde{q}(\theta)=\tilde{q}\left(\widetilde{p}^{-1}(p)\right)=q(p)$.
} 
an unemployed worker and $\widetilde{W}(\varepsilon)$ the expected discounted utility of an employed worker with a match-specific productivity term $\varepsilon$, hereafter somewhat imprecisely referred to as her type. Then $\widetilde{W}(\varepsilon)$ is defined as

$$
(r+s) \widetilde{W}(\varepsilon)=w(\varepsilon)-\psi(e(\varepsilon)) .
$$

The expected discounted value of a worker being matched is

$$
W=\int_{\varepsilon_{c}}^{\bar{\varepsilon}} \widetilde{W}(\varepsilon) d H+H\left(\varepsilon_{c}\right) U .
$$

The expected discounted utility of an unemployed worker is given by

$$
(r+s) U=z+p(W-U),
$$

where $z$ is the utility flow when unemployed.

Let $V$ denote the expected discounted value of a firm with a vacancy and $\widetilde{J}(\varepsilon)$ the expected discounted value of a filled job with a worker of type $\varepsilon$, where $\widetilde{J}(\varepsilon)$ is defined as

$$
(r+s) \widetilde{J}(\varepsilon)=y(e(\varepsilon), \varepsilon)-w(\varepsilon) .
$$

The expected value of a firm being matched is

$$
\begin{aligned}
J & =\int_{\varepsilon_{c}}^{\bar{\varepsilon}} \widetilde{J}(\varepsilon) d H+H\left(\varepsilon_{c}\right) V \\
& =\int_{\varepsilon_{c}}^{\bar{\varepsilon}} \frac{y(e(\varepsilon), \varepsilon)-w(\varepsilon)}{r+s} d H+H\left(\varepsilon_{c}\right) V .
\end{aligned}
$$

The value of a vacancy can thus be written as

$$
r V=-c+q(J-V) .
$$

For our subsequent analysis it is convenient to use the concept of worker rents associated with a match. The rents from a match reflect the workers' expected "capital gain" of being matched to a vacancy. Note that the expected rent associated with a match may be lower than the expected rent associated with employment, because not all matches need to end up in employment. The expected worker rents of a match can be expressed as 


$$
\begin{aligned}
R & \equiv W-U \\
& =\int_{\varepsilon_{c}}^{\bar{\varepsilon}}\left[\frac{w(\varepsilon)-\psi(e(\varepsilon))}{r+s}-U\right] d H .
\end{aligned}
$$

Using the definition of worker rents, the expected income of an unemployed worker takes a particularly simple form

$$
(r+s) U=z+p R
$$

That is, the flow value of an unemployed worker is equal to the utility flow when unemployed plus the expected gain from search, which is equal to the matching rate times the expected rent associated with a match. The total expected surplus of a match is $S \equiv J-V+R$, or (using equations (3) and (4))

$$
(r+s) S=\int_{\varepsilon_{c}}^{\bar{\varepsilon}}[y(e(\varepsilon), \varepsilon)-\psi(e(\varepsilon))-(r+s) U-(r+s) V] d H
$$

\section{Generalized competitive search equilibrium}

Our equilibrium concept is the competitive search equilibrium (Moen 1997), which combines competitive price determination and search frictions. One of its core element is the unique relationship between the attractiveness of the offered wage contract and the expected rate at which the vacancy is filled. This relationship can be derived in several alternative settings. Moen (1997) assumes that a market maker creates submarkets, and shows that the same equilibrium can be obtained if firms advertise wages. This interpretation is further developed in Mortensen and Wright (2002). Mortensen and Pissarides (1999, section 4.1) interpret the market maker as a "middle man" (like a job center) that sets the wage. In Acemoglu and Shimer (1999a and 1999b) the labor market is divided into regional or industrial submarkets offering potentially different wages. In the present paper we choose the interpretation that firms advertise wage contracts.

To characterize the unique relationship between the wage contract and the arrival rate of workers, let $U^{*}$ denote the equilibrium utility of a searching 
worker. The queue length of workers adjusts so that any worker who applies to any given firm must get an expected utility equal to $U^{*}$. That is,

$$
z+p R=(r+s) U^{*}
$$

which defines a unique, decreasing relationship between $R$, the expected rents associated with a match, and the probability rate $p$ at which the worker is matched. Since $q=q(p)$, there is a unique relationship between the arrival rate of applicants to a firm and the value of rents that this firm offers; $q=$ $q(p(R))$.

Let $\Phi$ denote the set of wage contracts $\phi=\left(w(\varepsilon), e(\varepsilon), \varepsilon_{c}\right)$ and let $\Phi^{D}$ denote the set of feasible contract. With private information, a feasible contract has to satisfy the incentive compatibility constraint and the participation constraint of the worker, to be specified below.

From the worker's perspective, the attractiveness of a wage contract is given by the expected value of being matched; $W=U+R$. For a given $U$, the attractiveness of a wage contract can therefore be summarized by $R$. Let $\Phi^{D}(R) \in \Phi^{D}$ denote the subset of feasible contracts that give the worker an expected rent $R$.

A firm chooses the wage contract $\phi$ that maximizes $V$, taking $U$ as given. The value of a vacancy can thus be expressed as

$$
r V=\max _{R} \max _{\phi \in \Phi^{D}(R)}-c+q(p(R))[J(\phi)-V] .
$$

The solution procedure for the optimal contract can be decomposed into two steps:

1. For a given $R$, solve for the contract $\phi \in \Phi^{D}(R)$ that maximizes $J$, the value of a match to the firm. Denote this optimal value by $J^{D}(R)$.

2. Maximize the value of a vacancy $V=-c+q(p(R))\left(J^{D}(R)-V\right)$ with respect to $R$, where $p(R)$ is defined by (7).

The resulting vacancy value can be written as $V^{\max }(U)$. Free entry then assures that

$$
V^{\max }(U)=0
$$


Definition. The generalized competitive search equilibrium (GCS-equilibrium) is a vector $\left(U^{*}, R^{*}, p^{*}, \phi^{*}\right)$ that solves the maximization problems 1 and 2 above and satisfies (9).

As a benchmark, we first solve for the equilibrium outcome in the special case where $\varepsilon$ and $e$ are observable and contractible. The contract still has to satisfy the worker's participation constraint. That is, $\widetilde{W}(\varepsilon) \geq U$ for all $\varepsilon \geq \varepsilon_{c}$. The problem of maximizing $J$ for a given expected rent $R$ (step 1) can be formulated as

$$
\begin{aligned}
\max _{w(\varepsilon), e(\varepsilon), \varepsilon_{c}}(r+s) J & =\max _{w(\varepsilon), e(\varepsilon), \varepsilon_{c}} \int_{\varepsilon_{c}}^{\bar{\varepsilon}}[\bar{y}+\varepsilon+\gamma e(\varepsilon)-w(\varepsilon)-(r+s) V] d H \\
& \text { s.t. } \\
(r+s) R & =\int_{\varepsilon_{c}}^{\bar{\varepsilon}}[w(\varepsilon)-\psi(e(\varepsilon))-(r+s) U] d H \\
\widetilde{W}(\varepsilon) & \geq U \quad \forall \varepsilon \geq \varepsilon_{c} .
\end{aligned}
$$

Suppose the participation constraint (11) does not bind for any $\varepsilon \geq \varepsilon_{c}$. Substituting the rent constraint (10) into the maximand simplifies the problem to

$$
\max _{e(\varepsilon), \varepsilon_{c}} \int_{\varepsilon_{c}}^{\bar{\varepsilon}}[\bar{y}+\varepsilon+\gamma e(\varepsilon)-\psi(e(\varepsilon))-(r+s) U-(r+s) V] d H-(r+s) R,
$$

with first order conditions

$$
\begin{aligned}
\psi^{\prime}(e(\varepsilon)) & =\gamma \text { for all } \varepsilon, \\
\bar{y}+\varepsilon_{c}+\gamma e\left(\varepsilon_{c}\right)-\psi\left(e\left(\varepsilon_{c}\right)\right) & =(r+s) U+(r+s) V .
\end{aligned}
$$

The first equation determines the efficient effort level. The second equation defines the efficient cut-off level, which equalizes the worker's net productivity with the outside options. Note that the solution is independent of $R$. Since workers are risk neutral, the participation constraint is easy to satisfy. For instance, the firm may set a constant wage, independent of worker type for all $\varepsilon \geq \varepsilon_{c}$, ensuring that the participation constraint never binds.

Consider now step 2 and let $S^{F}$ denote the full information match surplus. The firm maximizes the value of a vacancy. As $J^{F}-V=S^{F}-R$, the firm solves 


$$
\max _{R}-c+q(p(R))\left(S^{F}-R\right),
$$

where $p(R)$ is defined by (7). In Appendix 1, we show that the optimal choice of $R$ satisfies the Hosios condition (Hosios, 1990)

$$
\frac{R^{F}}{S^{F}-R^{F}}=\frac{\eta}{1-\eta}
$$

where $\eta$ denotes the absolute value of the elasticity of $q$ with respect to $\theta=v / u$. We refer to the equilibrium as the GCS -equilibrium with full information and denote it by $\left(U^{F}, R^{F}, p^{F}, \phi^{F}\right)$.

\section{Characterizing GCS-equilibrium}

When $e$ and $\varepsilon$ are private information, we have to specify the relevant incentive compatibility constraint, which ensures that a worker has an incentive to truthfully reveal her type. In Appendix 2, we show that this incentive compatibility constraint can be expressed as

$$
\omega^{\prime}(\varepsilon)=\psi^{\prime}(e(\varepsilon)) / \gamma
$$

where $\omega$ is the utility flow of the worker as defined by equation (2). If a worker's type increases by one unit, she can reduce her effort by $1 / \gamma$ units and still obtain the same output, thereby increasing her utility by $\psi^{\prime}(e(\varepsilon)) / \gamma$ units. Incentive compatibility requires that the worker obtains the same gain by reporting her type truthfully.

Using equation (16) the rent to a worker of type $\varepsilon, \widetilde{R}(\varepsilon)$, can be written as

$$
(r+s) \widetilde{R}(\varepsilon)=\int_{\varepsilon_{c}}^{\varepsilon} \frac{\psi^{\prime}(e(\varepsilon))}{\gamma} d \varepsilon+(r+s) \widetilde{R}\left(\varepsilon_{c}\right) .
$$

The participation constraint requires that $\omega\left(\varepsilon_{c}\right)=(r+s) U$ for $\varepsilon_{c}>\underline{\varepsilon}$, hence $\widetilde{R}\left(\varepsilon_{c}\right)=0$ for $\varepsilon_{c}>\underline{\varepsilon}$. Note that contracts that prescribe more effort from low-type workers must give larger rents to high types to keep the incentive compatibility constraint satisfied.

A first question that arises is whether the GCS-equilibrium with full information $\left(U^{F}, R^{F}, p^{F}, \phi^{F}\right)$ is still feasible. 
Lemma 1 a) For $\varepsilon_{c}^{F}>\underline{\varepsilon}$ the GCS-equilibrium with full information is not feasible when $\varepsilon$ and $e$ are private information to the worker.

b) For $\varepsilon_{c}^{F}=\underline{\varepsilon}$ the GCS-equilibrium with full information is feasible with private information if and only if $R^{F}>\bar{R}$, where

$$
\bar{R}=\int_{\underline{\varepsilon}}^{\bar{\varepsilon}} \frac{\varepsilon-\underline{\varepsilon}}{r+s} d H(\varepsilon) .
$$

Proof. a) Suppose the full information equilibrium is feasible. Denote the full information output level by $y^{F}$. The participation constraint (11) and equation (13) imply that $y^{F}\left(\varepsilon_{c}\right)=w\left(\varepsilon_{c}\right)$ (since $V=0$ in equilibrium). From equations (17), (12) and (1) it follows that $(r+s) \widetilde{R}^{\prime}(\varepsilon)=1=d y / d \varepsilon$ (full incentives). As a result, $y^{F}(\varepsilon)=w(\varepsilon)$ for all $\varepsilon \geq \varepsilon_{c}$, and thus profits are zero. Hence, no firm enters the market, which is inconsistent with equilibrium.

b) For $\varepsilon_{c}=\underline{\varepsilon}$ the participation constraint allows that $(r+s) U<y^{F}(\underline{\varepsilon})$ and hence that $w\left(\varepsilon_{c}\right)<y^{F}\left(\varepsilon_{c}\right)$. Since the first-best effort level implies that $\psi^{\prime}(e(\varepsilon))=\gamma$, the incentive compatibility constraint requires that $\widetilde{R}(\varepsilon) \geq \frac{\varepsilon-\varepsilon}{r+s}$. To implement the full information equilibrium with private information, we must thus have that $R^{F} \geq \bar{R}$. If $R^{F}>\bar{R}$, the full information equilibrium can be implemented by setting $\widetilde{R}(\underline{\varepsilon})=R^{F}-\bar{R}$.

In what follows we consider the case where $R^{F}<\bar{R}$. We derive the equilibrium by following the two-step procedure laid out above.

Step 1: Optimal wage contracts given $R$ The firm chooses the contract that maximizes $J$ given $R$. Clearly, this is equivalent to the problem of maximizing $S=J-V+R$ given $R$. We maximize the match surplus $S$ rather than $J$, as this offers a more interesting interpretation of the Lagrangian parameter. Equations (1) and (6) imply that the firm's problem is

$$
\max _{w(\varepsilon), e(\varepsilon), \varepsilon_{c}} \int_{\varepsilon_{c}}^{\bar{\varepsilon}}[\bar{y}+\varepsilon+\gamma e(\varepsilon)-\psi(e(\varepsilon))-(r+s) U-(r+s) V] d H,
$$

$$
\begin{aligned}
\text { s.t. } & \\
\omega^{\prime}(\varepsilon) & =\psi^{\prime}(e(\varepsilon)) / \gamma \\
\omega\left(\varepsilon_{c}\right) & =(r+s) U, \\
(r+s) R & =\int_{\varepsilon_{c}}^{\bar{\varepsilon}}[\omega(\varepsilon)-(r+s) U] d H,
\end{aligned}
$$


where we have used that the rent constraint always binds. This is an optimal control problem with $e$ as the control variable and $\omega(\varepsilon)$ as the state variable. Denote the Lagrangian parameter associated with the rent constraint (18) by $\alpha$ and the solutions to $S$ by $S^{M}(R ; U)$.

Proposition 1 The optimal contract $\phi^{M}(R ; U)$ is defined by

a) The first order condition for the effort level:

$$
\gamma-\psi^{\prime}(e(\varepsilon))=\alpha \frac{1-H(\varepsilon)}{h(\varepsilon)} \psi^{\prime \prime}(e(\varepsilon)) / \gamma
$$

b) The optimal cut-off level, given by either $\varepsilon_{c}=\underline{\varepsilon}$ or

$\left[\bar{y}+\varepsilon_{c}+\gamma e\left(\varepsilon_{c}\right)-\psi\left(e\left(\varepsilon_{c}\right)\right)-(r+s) U-(r+s) V\right] h\left(\varepsilon_{c}\right)=\alpha\left(1-H\left(\varepsilon_{c}\right)\right) \frac{\psi^{\prime}\left(e\left(\varepsilon_{c}\right)\right)}{\gamma}$

c) The rent-constraint defined by equation (18).

Proof. See Appendix 3.

In order to understand the conditions, recall that $\alpha$ denotes the shadow flow value of worker rents for the match surplus $S^{M}(R ; U)$. More precisely,

$$
(r+s) S_{R}^{M}=\alpha,
$$

where the subscript $R$ denotes the derivative with respect to $R .^{3}$

The two first-order conditions generalize optimal contracts with private information (as in e.g. Laffont and Tirole, 1993) for a setting with search frictions. Without frictions the shadow value of rents $\alpha$ would be equal to 1. For $\alpha=0$, the first-order conditions coincide with those of the fullinformation case. As shown above, this is only feasible when $R^{F} \geq \bar{R}$.

Consider the optimal effort equation (19) and suppose the effort level of a type $\hat{\varepsilon}$ worker increases by one unit. The left-hand side of equation (19) captures the resulting efficiency gain $\gamma-\psi^{\prime}(e(\hat{\varepsilon}))$. The right-hand side captures the costs associated with an increase in effort. A one unit increase in effort of a type $\hat{\varepsilon}$ worker increases the rents of all workers above $\hat{\varepsilon}$ by $\psi^{\prime \prime}(e(\hat{\varepsilon})) / \gamma$ units (from equation 17) and the shadow value of this rent is $\alpha$. The likelihood of obtaining a worker of type $\hat{\varepsilon}$ is reflected in $h(\hat{\varepsilon})$, while the

\footnotetext{
${ }^{3}$ Given that $h$ has an increasing hazard rate $((1-H(\varepsilon)) / h(\varepsilon)$ decreasing in $\varepsilon)$ and $\psi^{\prime \prime \prime}(e) \geq 0$ the equation (19) implies that $e(\varepsilon)$ is increasing in $\varepsilon$.
} 
measure of workers with higher match-specific productivity is $1-H(\hat{\varepsilon})$. This explains the factor $(1-H(\hat{\varepsilon})) / h(\hat{\varepsilon})$.

The left-hand side of the cut-off equation (20) shows the net productivity loss of increasing $\varepsilon_{c}$. The right-hand side represents the gain in terms of reduced rents, which have a shadow flow value $\alpha$. In Appendix 4, we show that the cut-off level is unique for a given $\alpha$.

Let $(a, b)$ denote a linear contract of the form $w=a+b y$. It is well known that the optimal non-linear contract can be represented by a menu $(a(\varepsilon), b(\varepsilon))$ of linear contracts. ${ }^{4}$ For any $b$, the worker chooses the effort level such that $\psi^{\prime}(e)=b \gamma$. Inserting this condition into equation (19), we obtain

$$
b(\varepsilon)=1-\alpha \frac{1-H(\varepsilon)}{h(\varepsilon)} \frac{\psi^{\prime \prime}(e)}{\gamma^{2}} .
$$

We refer to $b(\varepsilon)$ as the incentive power of the optimal contract.

Proposition $2 S^{M}$ and $\phi^{M}$ have the following properties:

a) The effort level $e(\varepsilon)$ is strictly increasing in $R$ for all $\varepsilon$, and the cut-off level $\varepsilon_{c}$ is decreasing in $R$.

b) The match surplus $S^{M}(R ; U)$ is increasing and concave in $R$.

c)If all types are hired $\left(\varepsilon_{c}=\underline{\varepsilon}\right)$, then

i) a shift in $U$ shifts $a(\varepsilon)$ but leaves $b(\varepsilon)$ unchanged for all $\varepsilon$.

ii) a shift in $U$ does not influence the marginal value of rents, i.e., $S_{R U}^{M}=0$.

Proof. See Appendix 5.

First consider result a). When the principal has more rents to dole out, she can afford to give stronger incentives to all workers. Furthermore, as the expected rent is decreasing in the cut-off level, a higher $R$ also implies that the principal can afford to hire workers of a lower types, by reducing $\varepsilon_{c}$. The Proposition states that the principal does both.

The first part of b), that the match surplus, $S^{M}$, increases in $R$, follows directly from the fact that the rent constraint bind. The second part of b), that $S^{M}$ is concave in $R$, follows from the convexity of the maximization problem, i.e. that the marginal return from higher effort or a lower cut-off level is decreasing.

\footnotetext{
${ }^{4}$ See, e.g., Laffont and Tirole, 1993.
} 
Result c) states that if all workers are hired, the workers' outside option $U$ does neither influence the incentive power of the contract nor the shadow value of rents. Intuitively, for a given cut-off, a change in $U$ (for a given $R$ ) only implies that more income is transferred to the worker, and effort level stays constant for all types. This property of the optimal contract will be used extensively below. ${ }^{5}$

Above we have derived the optimal static (tenure independent) contract.

Lemma 2 The optimal dynamic contract repeats the static contract, provided that the firm can commit not to renegotiate the contract.

Proof. See Appendix 6.

Providing incentives is costly for firms, as it yields information rents to the inframarginal workers. Deferred compensation or other time dependent wage contracts do not reduce this information rent, as they do not reduce the rent high types can obtain by pretending to be low types. Furthermore, deferred compensation does not influence the participation constraint at the hiring stage. It may loosen the participation constraint for tenured workers, but this has no value to the firm as the worker's outside option is time independent.

Step 2: Optimal sharing rules A firm maximizes $V(R)$ defined by

$$
\begin{aligned}
r V(R) & =-c+q(p(R))\left(J^{M}(R ; U)-V\right) \\
& =-c+q(p(R))\left(S^{M}(R ; U)-R\right),
\end{aligned}
$$

where $p(R)$ is defined by equation (7). This problem is similar to the maximization problem under full information, defined by equation (14). The only difference is that the match surplus is now increasing in $R$, so that

\footnotetext{
${ }^{5}$ If the match productivities $\varepsilon$ where correlated between firms, a worker's outside option would increase with $\varepsilon$. However, $U^{\prime}(\varepsilon)<1 /(r+s)$ would still hold and $U^{\prime}(\varepsilon)$ would be smaller when the correlation is weaker. The incentive compatibility constraint would be unaltered. Furthermore, the participation constraint would still only bind for the lowest type provided that the correlation is not too high. Hence, our main argument would still hold. However, the rents associated with a given contract and thus also $\bar{R}$ would be lower.
} 
$\frac{\partial J^{M}(R ; U)}{\partial R}=S_{R}^{M}-1>-1$. In Appendix 7, we show that the first order condition for the step 2 maximization problem satisfies

$$
\left(1-S_{R}^{M}\right) \frac{R}{S^{M}-R}=\frac{\eta}{1-\eta},
$$

where $\eta$ denotes as before the absolute value of the elasticity of $q$ with respect to $\theta=v / u$. We refer to this equation as the modified Hosios condition. We denote this generalized competitive search equilibrium by $\left(U^{*}, R^{*}, p^{*}, \phi^{*}\right)$.

Proposition 3 The generalized competitive search equilibrium satisfies the modified Hosios condition.

The modified Hosios condition states that the workers's share of the match surplus increases with the marginal value of worker rents, $S_{R}^{M}$. Thus, a smaller fraction of the match surplus is allocated to job creation. When $S_{R}^{M}=$ 0, equation (23) is identical to the Hosios condition with full information given by equation (15). With full information, a wage increase is purely redistributional. It reduces the value of a match for the firm by exactly the same amount as it increases its value to the worker. With private information this no longer holds. A one unit increase in $R$ increases the match surplus $S^{M}$ by $S_{R}^{M}$ units, thereby reducing the firm's wage cost by $1-S_{R}^{M}$ units.

The competitive search equilibrium with full information maximizes the asset value of unemployed workers given that firms break even (Acemoglu and Shimer, 1999b). This property also holds for the GCS-equilibrium:

Lemma 3 The generalized competitive search equilibrium maximizes $U$ given the free entry constraint $V=0$ and the relevant information constraints.

Proof. Suppose to the contrary. In this case there exists a wage contract $\tilde{\phi}$ such that $U(\tilde{\phi})=\tilde{U}>U^{*}$ and $V=0$. By definition a firm offering $\tilde{\phi}$ breaks even at $U=\tilde{U}$. Thus, the firm makes a strictly positive profit if it advertises this contract when $U=U^{*}<\tilde{U}$ (recall that $V$ only depends on $U$ ). But then $\phi^{*}$ cannot be a profit-maximizing wage contract, a contradiction.

It is well known that the competitive search equilibrium may not be unique, as our assumption regarding the matching function imposes few restrictions on the elasticity $\eta(\theta)$. (If there are more than one equilibrium, they all give rise to the same value of $U$ and are thus equivalent from a welfare point of view). When doing comparative static's it is convenient that the 
equilibrium is unique, and we therefore assume that the matching function is Cobb-Douglas, $x(u, v)=A u^{\beta} v^{1-\beta}$. It follows that $\eta=\beta$, and the modified Hosios condition is

$$
\left(1-S_{R}^{M}\right) \frac{R}{S^{M}-R}=\frac{\beta}{1-\beta} .
$$

Lemma 4 For $x(u, v)=A u^{\beta} v^{1-\beta}$, the GCS-equilibrium uniquely determines $U^{*}, R^{*}$ and $p^{*}$.

Proof. The uniqueness of $U^{*}$ is ensured by Lemma 3. We will show that (24) uniquely defines $R$. The uniqueness of $p^{*}$ is then ensured by equation (7). For a given $U=U^{*}$ we know from Proposition $2 \mathrm{~b}$ that $\left(1-S_{R}^{M}\right)$ is increasing in $R$. Since $S_{R}^{M}<1, S^{M}-R$ is also decreasing in $R$. But then the left-hand side of (24) is strictly increasing in $R$ so that (24) has a unique solution.

\section{Applications}

In this section we address the effects of aggregate shocks on sharing rules (wages), incentives, and unemployment. Instead of specifying a fully dynamic model, we analyze how parameter shifts change the wage contract and the unemployment rate. Both Shimer (2005) and Mortensen and Nagypal (2006) argue that the analysis of productivity shocks can be carried out without explicitly modelling the dynamics. An adequate approximation is to do comparative statics with respect to the productivity variable. Furthermore, as our contribution is on the conceptual side rather than on the quantitative side and we are able to get clear-cut analytical results we have decided not to calibrate the model and do numerical simulations. We first assume that all worker types are hired, i.e. $\varepsilon_{c}=\underline{\varepsilon}$. We return to the case with an interior cut-off level in section 5.3. ${ }^{6}$

In general, a shift in parameters changes the incentive power $b(\varepsilon)$ of the optimal contract even for given values of $R$ and $U \ldots$. However, some shifts do not, and we refer to these as information-neutral shifts. Such shifts only influence the incentive power of the wage contract through their effects on $R$ and $U$. Information-neutral shifts are

\footnotetext{
${ }^{6}$ In Appendix 8 we show that $\varepsilon_{c}=\underline{\varepsilon}$ and simultaneously $R^{F}<\bar{R}$ is indeed possible.
} 
- Changes in general (type- and effort-independent) productivity $\bar{y}$. This may be interpreted as changes in input prices (e.g. oil prices).

- Changes in the value of unemployment benefits /value of leisure $z$.

- Changes in the search cost $c$ and the matching function parameter $A$.

It follows directly from the first order condition for optimal incentive power (equation 21) that these shifts do not influence $b(\varepsilon)$.. By contrast, shifts in the distribution of $\varepsilon$ and the importance of unobservable effort, $\gamma$, influences the optimal $b(\varepsilon)$ directly.

As we will see, information-neutral shifts in productivity $\bar{y}$ with an exogenous cut-off lead at most to rent rigidity. As shown in Brugerman and Moscarini (2007), this is not sufficient to fully explain the Shimer paradox. However, information changing shifts or information neutral shifts with an endogenous cut-off may cause output and worker rents to move in different directions, thereby violating assumption 1a) in Brugerman and Moscarini. We show that in this case there are no bounds on how large the effects may be.

\subsection{Information-neutral shifts}

The effect of information-neutral shifts only depends on their effect on the equilibrium match surplus $S^{*}=S^{M}\left(R^{*}, U^{*}\right)$. Let $S_{R}^{*} \equiv S_{R}^{M}\left(R^{*}, U^{*}\right)$ and let $x$ denote (a vector of) information-neutral parameters in the model.

Lemma 5 An information-neutral shift moves $S^{*}, R^{*}$ and $J^{*}$ in the same direction, i.e., $d S^{*}, d R^{*}$ and $d J^{*}$ all have the same sign.

Proof. See Appendix 9.

Proposition 4 Suppose a shift in an information-neutral parameter $x$ increases $S^{*}$. Provided that $\varepsilon_{c}=\underline{\varepsilon}$, such a shift

a) reduces the worker's share of the match surplus,

b) increases the incentive power $b(\varepsilon)$ of the wage contract and hence also effort for all $\varepsilon$. 
Proof. From Lemma 5 we know that $R^{*}$ increases, and hence that $S_{R}$ decreases. The worker's share of the surplus is (from equation, 24)

$$
\frac{R^{*}}{S^{*}-R^{*}}=\frac{\beta}{1-\beta} \frac{1}{1-S_{R}},
$$

which thus decreases in $S^{*}$. Part a) of the proposition thus follows. From Proposition 2a we know that an increase in $R$ increases $e(\varepsilon)$ for all $\varepsilon$ and thereby also increases the incentive power $b(\varepsilon)$. This proves part b).

An information-neutral change that increases the match surplus increases the worker's rents for a given sharing rule. Hence, the marginal value of worker rents decreases, and in response the firm reduces the share of the surplus allocated to the worker.

Shifts in $\bar{y}$. A shift in $\bar{y}$ has two effects on $S^{*}$. On the one hand, it increases the value of a match, for a given $U$. On the other hand, it increases the outside option $U$. However, since there is a time delay before an unemployed worker finds a job, the former effect dominates, and $S^{*}$ increases. (See Appendix 10 for a formal proof.)

Thus, from Proposition 4 we know that a drop in $\bar{y}$ increases the worker's share of the surplus. This is an interesting observation, and is relevant for the discussion about rigid wages following the findings in Shimer (2005). As discussed in the introduction, Shimer documents empirical regularities of the business cycle that the standard matching model of the labor market hardly can account for. With private information, the workers' share of the surplus is counter-cyclical. After a negative shock to $\bar{y}$, the match surplus falls. Hence, for a given sharing rule, the shadow value of worker rents increases. As a result, firms find it optimal to increase the worker's share of the surplus. Thus, wages are more rigid, and the unemployment rate more volatile than in the standard model without private information. This result is related to Hall (2005). He argues that due to social norms, the worker's share of the match surplus is counter-cyclical. ${ }^{7}$ Our model generates a counter-cyclical sharing rule as an optimal response to changes in aggregate variables in the presence of private information.

As a fall in $\bar{y}$ reduces $S^{*}$, we have from Proposition 4 that the incentive power of the equilibrium wage contracts measured by $b(\varepsilon)$ falls for all $\varepsilon$.

\footnotetext{
${ }^{7}$ Hall (2004b) also shows that wage stickiness may be the result of alternative specifications of the bargaining procedure or of self-selection among workers.
} 
Loosely interpreted, the model thus predict that there should be less variable pay when aggregate productivity is low.

Shifts in unemployment benefits. An increase in $z$, unemployment benefits or value of leisure decreases $S^{*}$ (see Appendix 10). Intuitively higher unemployment benefits increase the workers' outside options, thus reducing the available match surplus.

An increase in unemployment benefits thus has a direct and an indirect effect on the unemployment rate. The direct or standard effect is that it lowers the match surplus, leading to less entry for a given sharing rule. Our new, indirect effect from Proposition 4 is that the share of the match surplus allocated to the worker increases, which further increases the unemployment rate.

Proposition 4 also shows that there is a link between unemployment benefits and the optimal wage contract. As $z$ increases and $S^{*}$ falls, there are less rents to the workers, and the incentive power of the wage contract falls. Thus, our model predicts that higher unemployment benefits are associated with less incentive pay and lower effort provision.

Shifts in the search cost $c$ and the matching technology parameter $A$. An increase in search cost $c$ increases $S^{*}$ (see Appendix 10). Again the change has a direct and an indirect effect on the unemployment rate, but now they go in opposite directions. The direct (standard) effect of an increase in $c$ is higher unemployment. For a given sharing rule, fewer firms enter the market and the unemployment rate increases. The indirect, countervailing effect is that the workers' share of the surplus falls (from Proposition 4). As a result, private information tends to dampen the effects of higher search costs on the unemployment rate.

Since the rents that are allocated to worker's in equilibrium increase, a higher value of $c$ implies that the wage contracts become more incentivepowered. If search costs are sufficiently large, it follows that $R^{F}>\bar{R}$, and all workers are given first-best incentives.

An increase in $A$ has the same effect as a fall in $c$. As match surplus increases, the worker's share of the surplus decreases, and the incentive power of the contract increases for all $\varepsilon$.

When search frictions are high it is more important for firms to speed up the hiring process by offering workers more rents. Thus, the cost of 
providing incentives in terms of higher worker rents falls, and firms increase the incentive power of the contract.

\subsection{Information-changing shifts}

In this subsection we analyze the effects of shifts that influence the optimal contract directly (for given values of $U$ and $R$ ).

Consider first a shift in the distribution of $\varepsilon$. To this end, write the matchspecific productivity term as $\varepsilon=k \mu$, where $\mu$ is symmetrically distributed on $[-1,1]$ and and $k$ is a scalar. Let $\widetilde{H}(\mu)$ denote the cumulative distribution function of $\mu$. Let $\bar{k}$ denote the value of $k$ such that $R^{*}=\bar{R}$ ( $\bar{k}$ is thus the highest possible $k$ for which the full-information equilibrium is feasible). We study the effects of an increase in $k$ for $k \geq \bar{k}$. On the one hand, an increase in $k$ increases the amount of private information workers possess. For a given $R$, the incentive power of the wage contract thus decreases, which tend to increase the marginal value of effort and thus $S_{R}^{M}$. On the other hand, an increase in $k$ implies that more rents are needed to increase workers' incentives, which tends to reduce the value of $S_{R}^{M}$. It turns out that if the private information problems are moderate ( $k$ relatively close to $\bar{k}$ ), the first effect dominates, and an increase in $k$ increases $S_{R}^{M}$. If private information problems are more severe, an increase in $k$ may reduce $S_{R}^{M}$. Define the "average" incentive power $\mathrm{as}^{8}$

$$
\bar{b}=\int_{\underline{\varepsilon}}^{\bar{\varepsilon}} b(\varepsilon) /(\bar{\varepsilon}-\underline{\varepsilon}) d \varepsilon .
$$

We show in Appendix 11 that a sufficient condition for ensuring that an increase in $k$ increases $S_{R}^{M}$ is that $\bar{b} \geq 1 / 2$. Note that if $R$ is close to $\bar{R}$, then $b$ is close to 1 for all $\varepsilon$.

As long as $\varepsilon_{c}=\underline{\varepsilon}$, an increase in $k$ reduces expected output: for a given $R$, an increase in $k$ implies that the optimal contract cuts back on worker effort, and output falls. The firm may compensate by increasing $R$, but due

\footnotetext{
${ }^{8}$ Note that $\bar{b}$ is generally not equal to the expected value of $b$, but is if $\varepsilon$ is uniformly distributed.
} 
to the envelope theorem this has only a second order effect on $U^{*}$. Hence, an increase in $k$ decreases $U^{*}$, and can thus be considered as a recession.

We want to illustrate with an example that the effects of changes in the information structure may lead to large changes in the unemployment rate relative to the change in output per worker (net of effort costs). To this end, suppose $k=\bar{k}$ initially, such that the full information outcome is achievable but with no slack. Let $\widetilde{y}$ denote expected output net of effort cost and recall that $u$ denotes the unemployment rate.

Proposition 5 Consider an increase in $k$, and suppose $k=\bar{k}$ initially. Let $u(k)$ and $\widetilde{y}(k)$ denote equilibrium values of $u$ and $\widetilde{y}$. Then,

$$
\lim _{k \rightarrow \bar{k}^{+}} \frac{d u(k)}{d \widetilde{y}(k)}=\infty .
$$

Proof. See Appendix 12.

Let us next consider the effects of shifts in the importance of unobservable effort $\gamma$.

Lemma 6 Given that $\varepsilon_{c}=\underline{\varepsilon}$, the marginal value of rents $S_{R}^{M}(R, U)$ is increasing in $\gamma$ provided that $\psi^{\prime \prime} /\left(\psi^{\prime}\right)^{2}$ is non-increasing in $e .^{9}$

Proof. See Appendix 13.

An increase in $\gamma$ tends to increase output, and is in that sense a positive shock. However, a shock may influence both $\bar{y}$ and $\gamma$. For instance, if a fall in $\bar{y}$ is caused by an increase in input prices (e.g. oil prices) and effort and energy are substitutes, a fall in $\bar{y}$ goes hand in hand with an increase in $\gamma$. Furthermore, the elasticity of the unemployment rate to average productivity may be arbitrarily high if the fall in $\bar{y}$ and increase in $\gamma$ implies that average productivity barely falls while the change in $\gamma$ is substantial.

More generally, information-changing shifts, if correlated with the business cycle, may increase the volatility of the unemployment rate. If workers have more private information during a downturn, or if unobservable effort is more important during a downturn, this will further increase the negative effect on the unemployment rate.

\footnotetext{
${ }^{9}$ This restriction is rather mild, and is satisfied for most convex functions. For instance, any polynomial of the form $\psi(e)=e^{n}(n>1)$ satisfies this condition, as well as the exponential function $\exp e$.
} 
Note also that for information-changing shifts the conditions in Brugerman and Moscarini (2007) are not satisfied. For instance, the effect of an increase in $k$, for $k$ close to $\bar{k}$, is a decrease in average productivity together with an increase in the expected rent. Hence, their assumption 1a is violated. The same may be true if a reduction in $\bar{y}$ goes hand in hand with an increase in $\gamma$. This is also true for shifts in the cut-off level discussed in the next subsection.

\subsubsection{Effects through the cut-off level}

So far we have assumed that all types are hired. In this subsection we briefly discuss the effects of the same shifts when $\varepsilon_{c}>\underline{\varepsilon}$. To facilitate reading we repeat the first-order condition for optimal cut-off level $\varepsilon_{c}$.

$$
\bar{y}+\varepsilon_{c}+\gamma e\left(\varepsilon_{c}\right)-\psi\left(e\left(\varepsilon_{c}\right)\right)-(r+s) U=\alpha \frac{\left(1-H\left(\varepsilon_{c}\right)\right)}{h\left(\varepsilon_{c}\right)} b\left(\varepsilon_{c}\right) .
$$

(where we have used that $\psi^{\prime}\left(e\left(\varepsilon_{c}\right)\right)=\gamma b\left(\varepsilon_{c}\right)$ ). The left-hand side is the match surplus associated with the marginal worker. It reflects the cost of increasing $\varepsilon_{c}$ and thereby not realizing matches with positive match surplus. The right-hand side reflects the gain of increasing $\varepsilon_{c}$ in terms of lower rents for higher types that are hired.

Proposition 6 For information-neutral productivity shifts, a fall in $\bar{y}$ or a rise in $z$ increases the cut-off level $\varepsilon_{c}$. A fall in $A$ or increase in $c$ decreases the cut-off level.

Proof. See Appendix 14.

A fall in $\bar{y}$ implies that the left-hand side of equation (25) falls (since $\bar{y}$ falls more than $(r+s) U)$. This tends to increase the cut-off level $\varepsilon_{c}$. Furthermore, we know that an increase in $\alpha$ also increases $\varepsilon_{c}$ (Appendix 5). A similar argument holds for shifts in $z, A$ and $c$.

Thus, in all cases the effects through the cut-off level seems to exacerbate our previous findings regarding the responsiveness of the unemployment rate to shocks. In particular, a negative shift in $\bar{y}$ increases the cut-off level, and thereby leads to a further increase in the unemployment rate. However, there is a caveat here: As $\varepsilon_{c}$ shifts up after a fall in $\bar{y}$, this tends to dampen the increase in $S_{R}^{M}$, and $S_{R}^{M}$ may even fall. However, this typically happens when 
the increase in $\varepsilon_{c}$ (and thus its adverse effect on the unemployment rate) is large.

Lemma 7 a) An increase in $k$ reduces the proportion of accepted matches provided that $b\left(\varepsilon_{c}\right) \geq 1 / 2$ and $\varepsilon_{c}$ is close to $\underline{\varepsilon}$.

b) Consider an increase in $\gamma$ combined with a reduction in $\bar{y}$ such that $U^{*}$ is unchanged. This reduces the proportion of accepted matches provided that $\psi^{\prime \prime} /\left(\psi^{\prime}\right)^{2}$ is non-increasing in e.

Proof. See Appendix 15.

The qualifier under point $\mathrm{b}$ ) is needed because an increase in $\gamma$, in addition to changing the information structure, also increases average productivity, and the latter effect tends to reduce $\varepsilon_{c}$.

\section{Final comments}

In this paper we define and characterize what we refer to as the generalized competitive search equilibrium, in which workers have private information regarding their effort and "type". In our model, the firms face a trade-off between extracting rents from workers and providing incentives to exert effort. Search frictions imply that the cost of leaving rents to the worker is lower than in the standard frictionless model, as worker rents save on search costs for the firms. We show that the resulting equilibrium satisfies what we refer to as the modified Hosios condition. We also analyze the equilibrium effects of changes in macroeconomic variables. Private information may increase the responsiveness of the unemployment rate to productivity changes. Furthermore, the incentive power of the wage contracts is positively related to high productivity, low unemployment benefits and high search frictions.

We want to point out that our definition of the generalized competitive search equilibrium is flexible, and can easily accommodate other forms of incentive problems. In a working paper version of this paper (Moen and Rosén 2006) we analyze both a model with shirking as in Shapiro and Stiglitz (1984) and a model with non-pecuniary aspects of employment. For instance, in the shirking model, workers are identical, but both worker effort and output are private information to the worker. Effort is either 0 or 1, and the effort cost is $\psi$. Let $g$ denote the probability rate that a shirking worker is detected, in which case she is fired. The non-shirking condition is then given by 


$$
\psi \leq g R .
$$

If we are in a region where the non-shirking constraint binds, the equilibrium rent is determined by $R^{*}=\psi / g$. A fall in $\bar{y}$ then has no impact on $R^{*}$, and we get complete rent rigidity.

It is our belief that developing search models with a richer structure than the standard Diamond-Mortensen-Pissarides model may add new insights, both within macroeconomics and different subfields of labor economics. In previous studies, inclusion of human capital in search models have improved our understanding of human capital formation. The present paper addresses questions relevant for both macroeconomic fluctuation and personnel economics within a search framework. Adding more structure to search models may therefore be a fruitful avenue for future research.

\section{Appendix}

\section{Appendix 1: Equation (15)}

Taking the derivative of (14) with respect to $R$ gives and utilizing that $V^{\prime}(R)=0$ in equilibrium gives

$$
q^{\prime}(p) p^{\prime}(R)\left(S^{F}-R\right)-q=0
$$

or, by simple manipulation,

$$
e l_{p} q(p) e l_{R} q(R)=\frac{R}{S^{F}(R)-R} .
$$

From (7) it follows that $e l_{R} p(R)=-1$. We want to show that $e l_{p} q(p)=-\frac{\eta}{1-\eta}$. To see this, let $p=\widetilde{p}(\theta)$ and $q=\widetilde{q}(\theta)$. Then

$$
\begin{aligned}
e l_{p} q(p) & =e l_{p} \widetilde{q}\left(\widetilde{p}^{-1}(p)\right) \\
& =\frac{e l_{\theta} \widetilde{q}(\theta)}{e l_{\theta} \widetilde{p}(\theta)} .
\end{aligned}
$$

Since $e l_{\theta} \widetilde{q}(\theta)=-\eta$ and $e l_{\theta} \widetilde{p}(\theta)=e l_{\theta}[\theta \widetilde{q}(\theta)]=1-\eta$, it follows that $e l_{p} q(p)=$ $-\frac{\eta}{1-\eta}$. The result thus follows. 


\section{Appendix 2: Proof of equation (16)}

A worker of type $\varepsilon$ that reports type $\widetilde{\varepsilon}$ receives a utility flow given by

$$
\widetilde{\omega}(\varepsilon, \widetilde{\varepsilon})=w(\widetilde{\varepsilon})-\psi\left(e(\widetilde{\varepsilon})-\frac{\varepsilon-\widetilde{\varepsilon}}{\gamma}\right) .
$$

Truth-telling requires that $\varepsilon=\arg \max _{\widetilde{\varepsilon}} \widetilde{\omega}(\varepsilon, \widetilde{\varepsilon})$. Since $\omega(\varepsilon)=\arg \max _{\widetilde{\varepsilon}} \widetilde{\omega}(\varepsilon, \widetilde{\varepsilon})$ it follows from the envelope theorem that

$$
\omega^{\prime}(\varepsilon)=\left.\frac{\partial \widetilde{\omega}(\varepsilon, \widetilde{\varepsilon})}{\partial \varepsilon}\right|_{\tilde{\epsilon}=\epsilon},
$$

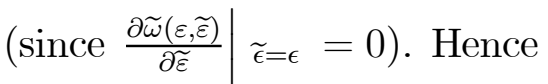

$$
\omega^{\prime}(\varepsilon)=\psi^{\prime}(e(\varepsilon)) / \gamma
$$

\section{Appendix 3: Proof of Proposition 1}

The associated Hamiltonian is

$$
\begin{aligned}
\mathcal{H}= & {[\bar{y}+\varepsilon+\gamma e(\varepsilon)-\psi(e(\varepsilon))-(r+s) U-(r+s) V] h(\varepsilon) } \\
& -\lambda \psi^{\prime}(e(\varepsilon)) / \gamma-\alpha\left[\int_{\varepsilon_{c}}^{\bar{\varepsilon}}(\omega(\varepsilon)-(r+s) U) d H-(r+s) R\right] .
\end{aligned}
$$

The first order conditions for $e(\varepsilon)$ can be expressed

$$
\left(\gamma-\psi^{\prime}(e(\varepsilon)) h(\varepsilon)=\lambda \psi^{\prime \prime}(e(\varepsilon)) / \gamma\right.
$$

Furthermore,

$$
\lambda^{\prime}(\varepsilon)=-\delta \mathcal{H} / \delta \omega=-\alpha h(\varepsilon) .
$$

Since $\bar{\varepsilon}$ is free it follows that $\lambda(\bar{\varepsilon})=0$. Thus, $\lambda=\alpha(1-H(\varepsilon))$. Inserted, this gives

$$
\gamma-\psi^{\prime}(e(\varepsilon))=\alpha \frac{1-H(\varepsilon)}{h(\varepsilon)} \psi^{\prime \prime}(e(\varepsilon)) / \gamma
$$

The optimal cut-off value $\varepsilon_{c}$ is obtained by setting $\mathcal{H}=0$ and inserting that $\omega\left(\varepsilon_{c}\right)=(r+s) U:$ 


$$
-\left[\bar{y}+\varepsilon_{c}+\gamma e\left(\varepsilon_{c}\right)-\psi\left(e\left(\varepsilon_{c}\right)\right)-(r+s) U-(r+s) V\right] h\left(\varepsilon_{c}\right)+\alpha\left(1-H\left(\varepsilon_{c}\right)\right) \frac{\psi^{\prime}\left(e\left(\varepsilon_{c}\right)\right)}{\gamma}=0 .
$$

\section{Appendix 4: Unique cut-off level}

Define

$$
\Psi\left(\varepsilon_{c}\right)=\bar{y}+\varepsilon_{c}+\gamma e\left(\varepsilon_{c}\right)-\psi\left(e\left(\varepsilon_{c}\right)\right)-(r+s) U-\alpha \frac{1-H\left(\varepsilon_{c}\right)}{h\left(\varepsilon_{c}\right)} \psi^{\prime}\left(e\left(\varepsilon_{c}\right)\right) / \gamma
$$

Equation (28) determines a unique $\varepsilon_{c}$ iff $\Psi\left(\varepsilon_{c}\right)=0$ is uniquely defined.

$\frac{d \Psi\left(\varepsilon_{c}\right)}{d \varepsilon_{c}}=1+\gamma \frac{d e}{d \varepsilon_{c}}-\psi^{\prime}\left(e\left(\varepsilon_{c}\right)\right) \frac{d e}{d \varepsilon_{c}}-\alpha \frac{\psi^{\prime}\left(e\left(\varepsilon_{c}\right)\right)}{\gamma} \frac{d \frac{1-H\left(\varepsilon_{c}\right)}{h\left(\varepsilon_{c}\right)}}{d \varepsilon_{c}}-\alpha \frac{1-H\left(\varepsilon_{c}\right)}{h\left(\varepsilon_{c}\right)} \frac{\psi^{\prime \prime}\left(e\left(\varepsilon_{c}\right)\right)}{\gamma} \frac{d e}{d \varepsilon_{c}}$

Inserting $-\alpha \frac{1-H\left(\varepsilon_{c}\right)}{h\left(\varepsilon_{c}\right)} \psi^{\prime \prime}\left(e\left(\varepsilon_{c}\right)\right) / \gamma=\psi^{\prime}\left(e\left(\varepsilon_{c}\right)\right)-\gamma$ (equation 19) and using that $h$ has an increasing hazard rate yields:

$$
\frac{d \Psi\left(\varepsilon_{c}\right)}{d \varepsilon_{c}}=1-\alpha \frac{\psi^{\prime}\left(e\left(\varepsilon_{c}\right)\right)}{\gamma} \frac{d \frac{1-H\left(\varepsilon_{c}\right)}{h\left(\varepsilon_{c}\right)}}{d \varepsilon_{c}}>0
$$

Hence, $\Psi\left(\varepsilon_{c}\right)=0$ is uniquely defined.

\section{Appendix 5: Proof of Proposition 2}

We first show the following property

Property P1: The cut-off level $\varepsilon_{c}$ is increasing in $\alpha$ (for a given $U$ ).

Proof. It is convenient to rewrite the cut-off equation (20) as

$$
\bar{y}+\varepsilon_{c}-(r+s) U-(r+s) V=\alpha \frac{1-H\left(\varepsilon_{c}\right)}{h\left(\varepsilon_{c}\right)} \frac{\psi^{\prime}\left(e\left(\varepsilon_{c}\right)\right)}{\gamma}-\left(\gamma e\left(\varepsilon_{c}\right)-\psi\left(e\left(\varepsilon_{c}\right)\right)\right) .
$$

Denote the left-hand side by $X_{L}\left(\varepsilon_{c}\right)$ and the right-hand side by $X_{R}\left(\varepsilon_{c} ; \alpha\right)$. Note that $X_{L}$ reflects the costs while $X_{R}$ reflects the gains from increasing $\varepsilon_{c}$. Obviously $X_{L}^{\prime}\left(\varepsilon_{c}\right)=1$. As the second order condition must be satisfied 
locally, $X_{L}(\varepsilon)$ crosses $X_{R}(\varepsilon ; \alpha)$ from below. It is therefore sufficient to show that around $\varepsilon=\varepsilon_{c}$ an increase in $\alpha$ shifts $X_{R}(\varepsilon ; \alpha)$ up.

$$
\begin{aligned}
\frac{\partial X_{R}\left(\varepsilon_{c} ; \alpha\right)}{\partial \alpha}= & \frac{1-H\left(\varepsilon_{c}\right)}{h\left(\varepsilon_{c}\right)} \frac{\psi^{\prime}\left(e\left(\varepsilon_{c}\right)\right)}{\gamma}+\alpha \frac{1-H\left(\varepsilon_{c}\right)}{h\left(\varepsilon_{c}\right)} \frac{\psi^{\prime \prime}\left(e\left(\varepsilon_{c}\right)\right)}{\gamma} \frac{d e}{d \alpha} \\
& -\left(\gamma-\psi^{\prime}\left(e\left(\varepsilon_{c}\right)\right)\right) \frac{d e}{d \alpha} .
\end{aligned}
$$

From equation (19) we have that $\gamma-\psi^{\prime}(e)=\alpha \frac{1-H}{h} \frac{\psi^{\prime \prime}}{\gamma}$. Hence the two last terms cancel out, and

$$
\frac{\partial X_{R}\left(\varepsilon_{c} ; \alpha\right)}{\partial \alpha}=\frac{1-H\left(\varepsilon_{c}\right)}{h\left(\varepsilon_{c}\right)} \frac{\psi^{\prime}\left(e\left(\varepsilon_{c}\right)\right)}{\gamma}>0,
$$

completing the proof of Property P1.

Proof of proposition $2 \mathrm{~b}$ ). Since the rent-constraint by definition is binding, it follows directly that $S^{M}(R, U)$ increases in $R$. To show that $S^{M}(R, U)$ is concave in $R$ it is sufficient to show that $\alpha$ is decreasing in $R$. Consider an increase in $R$ and suppose to the contrary that $\alpha$ increases. From Property P1 we know that $\varepsilon_{c}$ is increasing in $\alpha$. From (19) and the assumptions on $\psi$ it follows that $e(\varepsilon)$ is decreasing in $\alpha$ for all $\varepsilon$. From (17) it follows that the rent for each type is decreasing, and thus that the expected rent is decreasing, a contradiction.

Proof of proposition 2a) From the proof of $2 \mathrm{~b}$ ) it follows that $\alpha$ increases in $R$, hence that $e(\varepsilon)$ is strictly increasing in $\varepsilon$ follows directly from (19) (since by assumption $\psi^{\prime}(e)$ is increasing and convex in $e$ ). That $\varepsilon_{c}$ is decreasing in $R$ follows directly from Property $\mathrm{P} 1$ and that $\alpha$ is decreasing in $R$.

Proof of proposition 2c) The results in part c) follows directly from the fact that when $\varepsilon_{c}=\underline{\varepsilon}, U$ only influences the maximization problem through the participation constraint $\omega(\underline{\varepsilon})=(r+s) U$. The first order condition for optimal effort as well as $\alpha$ is independent of $U$.

\section{Appendix 6: Proof of Lemma 2}

We want to show that the optimal time-independent contract is optimal within the larger class of time-dependent contracts as well. A similar proof, based on Baron and Besanko (1984) can be found in Fudenberg and Tirole (1991, p. 299). To simplify the proof and avoid uninteresting technicalities we assume that time is discrete. We consider first the case where the cut-off level is $\underline{\varepsilon}$. This will be modified at the end. 
The revelation principle still holds. Hence, it is sufficient to study the set of contracts that map the worker's (reported) type into a sequence of wages and effort levels $\left\{w_{t}(\varepsilon), e_{t}(\varepsilon)\right\}_{t=0}^{\infty}$, where $t$ denotes the tenure of the worker in question.

Let $\pi_{t}\left(\varepsilon, e_{t}\right)=\bar{y}+\varepsilon+\gamma e_{t}(\varepsilon)-w_{t}(\varepsilon)$. The expected discounted profit to the firm is given by

$$
\Pi=E^{\varepsilon} \Sigma_{t=0}^{\infty} \pi_{t}\left(\varepsilon, e_{t}\right) \delta^{t}
$$

where $\delta=\frac{1-s}{1+r}$ is the discount factor, including the exit rate of the worker. The expected discounted utility of a worker of type $\varepsilon$ who announce type $\widetilde{\varepsilon}$ is given by

$$
\bar{W}(\varepsilon, \widetilde{\varepsilon})=\Sigma_{t=0}^{\infty}\left[w_{t}(\widetilde{\varepsilon})-\psi(\varepsilon, e(\widetilde{\varepsilon}))\right] \delta^{t}
$$

where

$$
\psi(\varepsilon, e(\widetilde{\varepsilon})) \equiv \psi\left(e(\widetilde{\varepsilon})-\frac{\varepsilon-\widetilde{\varepsilon}}{\gamma}\right) .
$$

Incentive compatibility requires that $\varepsilon=\arg \max _{\widetilde{\varepsilon}} \bar{W}(\varepsilon, \widetilde{\varepsilon})$. Let $W(\varepsilon) \equiv$ $\bar{W}(\varepsilon, \varepsilon)$.

The optimal dynamic contract solves

$$
\max _{\left\{w_{t}(\varepsilon), e_{t}(\varepsilon)\right\}_{t=0}^{\infty}} E^{\varepsilon} \Sigma_{t=0}^{\infty} \pi_{t}\left(\varepsilon, e_{t}\right) \delta^{t}
$$

subject to

- Incentive compatibility: $\varepsilon=\arg \max _{\widetilde{\varepsilon}} \bar{W}(\varepsilon, \widetilde{\varepsilon})$

- Individual rationality: $W(\varepsilon) \geq U$ for all $\varepsilon$. This constraint only binds for $\underline{\varepsilon}$.

Note that the participation constraint regards the expected discounted utility of all future periods. It does not require that the utility flow of employed workers is higher than the utility flow of unemployed workers in all periods. Thus, deferred compensation with increasing wage-tenure profile is allowed for.

Let $C^{d}=\left\{w_{t}^{d}(\varepsilon), e_{t}^{d}(\varepsilon)\right\}_{t=0}^{\infty}$ denote an optimal contract within the larger set of time-dependent contracts, and let $C^{*}=\left\{w^{*}(\varepsilon), e^{*}(\varepsilon)\right\}_{t=0}^{\infty}$ denote the time-independent contract. We want to show that $C^{d}$ is equivalent to $C^{*}$, in the sense that it implements the same effort level in each period, the same discounted expected profit to the firm, and the same expected discounted rents to the workers. 
Suppose $C^{d} \neq C^{*}$. Then $C^{d}$ cannot implement a time independent effort level, as this contract by definition is dominated by the optimal static contract $C^{*}$. Suppose therefore that $C^{d}$ does not implement a time independent effort level. We will show that this leads to a contradiction.

To this end, consider the random time-independent stochastic mechanism $C^{d S}$, defined as follows: each period, the contract $\left(w_{t}^{d}(\varepsilon), e_{t}^{d}(\varepsilon)\right)$ is im-

plemented with probability $\frac{\delta^{t}}{1-\delta}$. By definition, this contract is both incentive compatible and satisfies the individual rationality constraint. Furthermore, it yields a higher expected profit to the firm than the static contract $\left(w^{*}(\varepsilon), e^{*}(\varepsilon)\right)$, since $C^{d}$ dominates $C^{*}$, and thus contradicts the optimallity of the latter mechanism in the class of time-independent contracts. It thus follows that $C^{d}=C^{*}$.

Finally, the same argument holds for any given cut-off value $\varepsilon_{c}$, and hence the optimal cut-off level with time-dependent contracts must be equal to the optimal cut-off level with time-independent contracts.

\section{Appendix 7: Equation (23)}

Taking the first order condition for the problem of maximizing $V$ defined by (22) gives

$$
q^{\prime}(p) p^{\prime}(R)\left(S^{M}(R ; U)-R\right)-q\left(1-S_{R}^{M}\right)=0
$$

or, by simple manipulation,

$$
e l_{p} q(p) e l_{R} q(R)=\left(1-S_{R}^{M}\right) \frac{R}{S^{M}-R},
$$

analogous to (27). By taking exactly the same steps as in Appendix 1 (23) follows.

\section{Appendix 8}

Let $\widetilde{\varepsilon}$ be a stochastic variable with finite support, and define the stochastic matching term as $\varepsilon=k \widetilde{\varepsilon}$. We will show that there exists an interval $(\underline{k}, \bar{k})$ such that for any $k$ in this interval the following holds: 1) $\bar{R}>R^{F}$, and 2) the cut-off level is equal to $\underline{\varepsilon}$. 
For sufficiently small values of $k$ we have that $\bar{R}<R^{F}$ and first best effort and hiring is feasible with $\varepsilon_{c}=\underline{\varepsilon}$. Define $\underline{k}$ as the value of $k$ such that $\bar{R}=R^{F}$. As workers have full incentives, $w^{\prime}(y)=1$. Since firms have positive profit it thus follows that $y(\underline{\varepsilon})>w(\underline{\varepsilon})$, otherwise firms would obtain zero profits. Thus, increasing the cut-off level has a first-order effect on expected surplus. Reducing the incentive power of the contract slightly only gives a second-order effect on expected surplus. Thus, for values of $k$ on an interval above $\underline{k}$ firms reduce the incentive power of the contract below first best and still hire all types.

\section{Appendix 9: Proof of Lemma 5}

Differentiating (24) gives (recall that by the very definition of neutral shifts we know that the functional form of $S_{R}(R)$ does not change)

$$
-S_{R R}^{*} R^{*} d R^{*}+\left(1-S_{R}^{*}\right) d R^{*}=\frac{\beta}{1-\beta}\left(d S^{*}-d R^{*}\right)
$$

or

$$
d S^{*}=\left[1-\frac{1-\beta}{\beta} S_{R R}^{*} R^{*}+\frac{1-\beta}{\beta}\left(1-S_{R}^{*}\right)\right] d R^{*}
$$

Since the coefficient before $d R^{*}$ is strictly positive $d R^{*}$ and $d S^{*}$ have the same sign. Rearranging (24) gives

$$
\begin{aligned}
J^{*} & \equiv S^{*}-R^{*} \\
& =\frac{1-\beta}{\beta} R^{*}\left(1-S_{R}^{*}\right)
\end{aligned}
$$

Differentiating gives

$$
d J^{*}=\frac{1-\beta}{\beta}\left(1-S_{R}^{*}-S_{R R}^{*} R^{*}\right) d R^{*}
$$

Since the coefficient before $d R^{*}$ is strictly positive $d J^{*}$ and $d R^{*}$ have the same sign.

Appendix 10: Proof that $S^{*}$ increases in $\bar{y}$ and $A$ and decreases in $z$ and $c$. 
i) Shifts in $\bar{y}$.

Consider a positive shift in $\bar{y}$. From lemma 3 we know that in equilibrium, $U^{*}$ is maximized, hence it is trivial to show that $U^{*}$ is increasing in $\bar{y}$.

Suppose that $S^{*}$ shifts down following an increase in $\bar{y}$.. From Lemma 5 it follows that $R^{*}$ and $J^{*}=S^{*}-R$ shifts down. The free entry condition then implies that $p$ falls. But then from (5) we have that $U^{*}$ falls, a contradiction.

ii) Shifts in $z, A$ and $c$.

Consider again the equilibrium condition (24). Shifts in $z, A$ and $c$ only influences the modified Hosios condition through their effects on the equilibrium value of $U^{*}$. Define $L\left(R ; U^{*}\right)$ as the left-hand side of $(24)$, so that the equilibrium condition can be written

$$
\begin{aligned}
L\left(R ; U^{*}\right) & \equiv\left(1-S_{R}^{M}(R)\right) \frac{R}{S^{M}\left(R, U^{*}\right)-R} \\
& =\frac{\beta}{1-\beta}
\end{aligned}
$$

The function $L$ is increasing in $R$ for a given value of $U^{*}$. As $S^{M}$ is decreasing in $U^{*}$, and $S_{R U}^{M}=0$ it follows that $L$ shifts up when $U^{*}$ increases. Hence $R^{*}$ is decreasing in $U^{*}$, as is $S^{*}$. From Lemma 3 we know that in equilibrium, $U^{*}$ is maximized, hence it is trivial to show that $U^{*}$ is increasing in $z$ and $A$ and decreasing in $c$. The claims thus follows.

\section{Appendix 11:}

Here we show that an increase in $k$ increases $S_{R}^{M}$ (i.e., increases $\alpha$ ) if $\bar{b} \geq 1 / 2$ is above $1 / 2$. In the proof of proposition (2) part $b$, see appendix 5 , we showed that $\alpha$ is decreasing in $R$. It is thus sufficient to show that for a given $\alpha$, an increase in $\gamma$ implies that the rent-constraint defined in equation (18) is no longer satisfied as the associated $R$ increases. Taking

the expectation of equation (17) and using that $\widetilde{R}\left(\varepsilon_{c}\right)=0$ it follows that expected rent can be expressed

$$
\begin{aligned}
(r+s) R & =\int_{-k}^{k} \int_{-k}^{\varepsilon} \frac{\psi^{\prime}(e(\varepsilon))}{\gamma} d \varepsilon d H(\varepsilon) \\
& =\int_{-k}^{k} \int_{-k}^{\varepsilon} b(e(\varepsilon)) d \varepsilon d H(\varepsilon)
\end{aligned}
$$


Using integration by parts gives

$$
\begin{aligned}
(r+s) R & =-\left.\right|_{-k} ^{k}(1-H) \int_{-k}^{\varepsilon} b(\varepsilon) d \epsilon+\int_{-k}^{k} b(\varepsilon)(1-H) d \varepsilon \\
& =\int_{-k}^{k} b(\varepsilon)(1-H) d \varepsilon .
\end{aligned}
$$

Now $\varepsilon=\mu k, H(\varepsilon)=\widetilde{H}(\varepsilon / k), h(\varepsilon)=\widetilde{h}(\varepsilon / k) / k$. Hence $(30)$ can be written as

$$
(r+s) R=\int_{-1}^{1} k b(k \mu)(1-\widetilde{H}(\mu)) d \mu
$$

From equation (21) we have that

$$
b(k \mu)=1-\alpha k \frac{1-\widetilde{H}(\mu)}{\widetilde{h}(\mu)} \frac{\psi^{\prime \prime}(e(k \mu))}{\gamma^{2}} .
$$

Now that $b(k \mu)$ is decreasing in $k$. Suppose not. Then $e(k \mu)$ increases, and hence also $\psi^{\prime \prime}(e(k \mu))$, in which case the right-hand side of $(32)$ decreases, and we have derived a contradiction.

Inserted into (31) the expression for $R$ can be rewritten as

$$
(r+s) R=\int_{-1}^{1} k\left[1-\alpha k \frac{1-\widetilde{H}(\mu)}{\widetilde{h}(\mu)} \frac{\psi^{\prime \prime}(e(k \mu))}{\gamma^{2}}\right](1-\widetilde{H}(\mu)) d \mu .
$$

Taking the derivative with respect to $k$ gives

$$
\begin{aligned}
& \frac{d(r+s) R}{d k} \\
= & \int_{-1}^{1}\left[1-2 \alpha k \frac{1-\widetilde{H}(\mu)}{\widetilde{h}(\mu)} \frac{\psi^{\prime \prime}(e(k \mu))}{\gamma^{2}}-k^{2} \alpha \frac{1-\widetilde{H}(\mu)}{\widetilde{h}(\mu)} \frac{\psi^{\prime \prime \prime}(e(k \mu))}{\gamma^{2}} \frac{d e(k \mu)}{d k}\right](1-\widetilde{H}(\mu)) d \mu \\
> & \int_{-1}^{1}\left[1-2 \alpha k \frac{1-\widetilde{H}(\mu)}{\widetilde{h}(\mu)} \frac{\psi^{\prime \prime}(e(k \mu))}{\gamma^{2}}\right](1-\widetilde{H}(\mu)) d \mu \\
= & \int_{-1}^{1}[2 b(k \mu)-1](1-\widetilde{H}(\mu)) d \mu .
\end{aligned}
$$


To get the result we have used that $\frac{d e(k \mu)}{d k}<0$ (since $b(k \mu)$ is decreasing in $k$ ) and that $\psi^{\prime \prime \prime}$ is positive and inserted from equation (32). Hence, a sufficient condition ensuring that an increase in $k$ increases $R$ for a given $\alpha$ is $\bar{b} \geq 1 / 2$.

Appendix 12: Proof of Proposition 5.

First we show that $\frac{d \widetilde{y}(\bar{k})}{d k}=0$. Write $\widetilde{y}(k)$ as

$$
\widetilde{y}(k)=\int_{-1}^{1}\left[\bar{y}+k \mu+\gamma e^{*}(k \mu, k)-\psi\left(e^{*}(k \mu, k)\right)\right] d \widetilde{H}(\mu),
$$

where $e^{*}(k \mu, k)$ denotes the effort level prescribed by the optimal contract as a function of $\mu$ and $k$. At $k=\bar{k}, e^{*}$ maximizes $\widetilde{y}(k)$, and due to the envelope theorem it follows that we can ignore the effects of a change in $k$ on $e^{*}$. Thus,

$$
\frac{d \widetilde{y}(\bar{k})}{d k}=\int_{-1}^{1} \mu d \widetilde{H}(\mu)=0 .
$$

The next step is to show that the equilibrium responses of $U$ and $S$ to a change in $k$ at $k=\bar{k}$ is zero. Taking the derivative of (8) for a given $U^{*}$, using that $J-V=S-R$ and using the envelope theorem gives

$$
r \frac{d V}{d k}=q\left(R^{*}\right) \frac{\partial S^{M}(R, \mu, \bar{k})}{\partial k}=0,
$$

since $(r+s) S^{M}(R, \mu, \bar{k})=\widetilde{y}(k)-(r+s) U$ and $\frac{d \widetilde{y}(\bar{y})}{d k}=0$. Hence $V^{\max }(U)$ does not change, and from the equilibrium equation (9) we have that $U^{* \prime}(\bar{k})=0$. Finally, we can write $S^{*}(k)=S^{M}\left(R^{*}, U^{*}, k\right)$, and since $S_{R}^{M}=0$ at $R=\bar{R}$ it follows that $S^{* \prime}(\bar{k})=0$.

Then we turn to $R^{*}$, which we write as $R^{*}=R^{*}(k)$. At $k=\bar{k}$, the derivative of $R^{*}(k)$ may not exist. Define $R^{* \prime}(\bar{k})=\lim _{k \rightarrow \bar{k}^{+}} R^{* \prime}(k)$. We want to show that $R^{* \prime}(\bar{k})>0$. Since $S^{*}$ is constant we know from equation (24) that $R^{*}(k)$ is increasing in $k$ at $k=\bar{k}$ if and only if $S_{R k}^{M}>0$, at this point, i.e., if $\frac{d \alpha(\bar{k})}{d k} \equiv \lim _{k \rightarrow \bar{k}^{+}} \alpha(k)>0$. Taking the expectation of equation (17) it follows that expected rent can be written as (since $\widetilde{R}(\underline{\varepsilon})=0$ ).

$$
\begin{aligned}
(r+s) R & =\int_{-k}^{k} \int_{-k}^{\varepsilon} \psi^{\prime}(e(\varepsilon)) / \gamma d \varepsilon d H(\varepsilon) \\
& =\int_{-k}^{k} \int_{-k}^{\varepsilon} b(e(\varepsilon)) d \varepsilon d H(\varepsilon)
\end{aligned}
$$


(since $\left.\gamma b=\psi^{\prime}\right)$. Suppose now, contrafactually, that $b(\varepsilon)=\hat{b}$ for all $\varepsilon$, where $\hat{b}$ is a constant in $(0,1]$. Then

$$
\begin{aligned}
R & =\int_{-k}^{k} \int_{-k}^{\varepsilon} \hat{b} d \varepsilon d H(\varepsilon) \\
& =\hat{b} k
\end{aligned}
$$

At $k=\bar{k}$, we know that $b=1$ for all $\varepsilon$, and thus that $R^{*}=\bar{R}=\bar{k}$. Taking the derivative with respect to $k$, still assuming $\hat{b}$ constant over types gives

$$
\left.\hat{b}^{\prime}(k)\right|_{k=\bar{k}}=-\frac{1}{\bar{k}}<0 .
$$

For $k<\bar{k}$ we know that $b$ is not constant in $\varepsilon$. However, it follows that $\left.\frac{d b(\varepsilon)}{d k}\right|_{k=\bar{k}} \geq\left.\hat{b}^{\prime}(k)\right|_{k=\bar{k}}$ for some $\varepsilon$. Furthermore, since $b(\varepsilon)$ is increasing in $\varepsilon$ for all $k<\bar{k}$ it follows that $\left.\frac{d b(\varepsilon)}{d k}\right|_{k=\bar{k}}$ is largest at $\varepsilon=\underline{\varepsilon}$, hence $\left.\frac{d b(\underline{\varepsilon})}{d k}\right|_{k=\bar{k}}<0$. From equation (21) we know that $\left.\frac{d \alpha}{d k}\right|_{k=\bar{k}}>0$. It follows that $R^{* \prime}(\bar{k})>0$ and hence also that $\lim _{k \rightarrow \bar{k}^{+}} \frac{d u}{d k}>0$. The result thus follows.

\section{Appendix 13: Proof of Lemma 6}

Consider the first order conditions for the optimal contract defined in Proposition 1. We want to show that an increase in $\gamma$ increases the Lagrange parameter $\alpha$. This is equivalent to showing that for a given $\alpha$, an increase in $\gamma$ implies that the rent-constraint defined in equation (18) is no longer satisfied, as $R$ has increased. From equation (33) it then follows that it is sufficient to show that a positive shift in $\gamma$ increases $b(\varepsilon)$ for all $\varepsilon$ for a given value of $\alpha$.

The first order condition for effort (19) reads

$$
\gamma\left[1-\psi^{\prime}(e(\varepsilon)) / \gamma-\alpha \frac{1-H(\varepsilon)}{h(\varepsilon)} \psi^{\prime \prime}(e(\varepsilon)) / \gamma^{2}\right]=0 .
$$

It is sufficient to show that an increase in $\gamma$, keeping $b(\varepsilon)=\psi^{\prime}(e(\varepsilon)) / \gamma$ constant, increases the LHS of this equation. The second order conditions then ensure that $\psi^{\prime}(e(\varepsilon)) / \gamma$ increases. Substituting in $b(\varepsilon)=\psi^{\prime}(e(\varepsilon)) / \gamma$ gives

$$
\gamma\left[1-b(\varepsilon)-\alpha \frac{1-H(\varepsilon)}{h(\varepsilon)} \frac{\psi^{\prime \prime}(e(\varepsilon)) b(\varepsilon)^{2}}{\psi^{\prime}(e(\varepsilon))^{2}}\right]=0 .
$$


For a given $b, e$ is increasing in $\gamma$, and it follows that the left-hand side is increasing in $e$ provided that $\frac{\psi^{\prime \prime}(e(\varepsilon))}{\psi^{\prime}(e(\varepsilon))^{2}}$ is decreasing.

\section{Appendix 14: Proof of Proposition 6}

Consider proposition (6). It is convenient to repeat the cut-off equation (20)

$$
-\left[\bar{y}+\varepsilon_{c}+\gamma e\left(\varepsilon_{c}\right)-\psi\left(e\left(\varepsilon_{c}\right)\right)-(r+s) U^{*}\right]+\alpha \frac{\left(1-H\left(\varepsilon_{c}\right)\right)}{h\left(\varepsilon_{c}\right)} \frac{\psi^{\prime}\left(e\left(\varepsilon_{c}\right)\right)}{\gamma}=0 .
$$

Denote the left-hand side by $X_{L}\left(\varepsilon_{c}\right)$, with all the variables (less $\varepsilon_{c}$ ) taking their equilibrium values. Note that $X_{L}\left(\varepsilon_{c}\right)$ denotes the marginal gain from increasing $\varepsilon_{c}$. As the second order condition must be satisfied locally, we know that $\partial X_{L} / \partial \varepsilon<0$ around $\varepsilon=\varepsilon_{c}$.

Consider first a shift in $\bar{y}$. We want to show that $\varepsilon_{c}$ decreases in $\bar{y}$. Suppose first that $\alpha$ is constant, independent of $\bar{y}$. Then effort is independent of $\bar{y}$ as well. Hence, the derivative of (34) reads

$$
\frac{\partial X_{L}\left(\varepsilon_{c}\right)}{\partial \bar{y}}=-1+(r+s) \frac{d U^{*}}{d \bar{y}}
$$

From Appendix 10 it follows that $(r+s) \frac{d U^{*}}{d \bar{y}}<1$. It thus have that $X_{L}$ shifts down and hence that $\varepsilon_{c}$ is decreasing in $\bar{y}$.

Suppose then that $\frac{d \alpha}{d \bar{y}}<0$. From Property P1 in Appendix 5 we know that $\varepsilon_{c}$ defined by (34) is increasing in $\alpha$ (even when the effects of an increase in $\alpha$ on $e$ is taken into account). Thus $\varepsilon_{c}$ falls even more than when $\alpha$ is constant.

Suppose then finally that $\frac{d \alpha}{d \bar{y}}>0$ (this we cannot rule out). We want to show that $\varepsilon_{c}$ is still decreasing in $\bar{y}$. Suppose not. From equation (21) we have that $b(\varepsilon)$ and thus effort is decreasing in $\alpha$ for all worker types. Using equation (17) the expected rents can be written as

$$
(r+s) R=\int_{\varepsilon_{c}}^{\bar{\varepsilon}} \int_{\varepsilon_{c}}^{\varepsilon} \frac{\psi^{\prime}(e(\varepsilon))}{\gamma} d \varepsilon d H
$$

Thus $R^{*}$ must fall if both $\alpha$ and $\varepsilon_{c}$ increases.

Consider then the modified Hosios-condition, which we can write as

$$
(1-\alpha) \frac{R^{*}}{S^{*}-R^{*}}=\frac{\beta}{1-\beta}
$$


Suppose first that $S^{*}$ increases in $\bar{y}$ (as it does for a constant cut-off). Then if $\alpha$ increases $R^{*}$ must increase in $\bar{y}$ as well. But then we have derived a contradiction. Suppose then that $S^{*}$ decreases in $\bar{y}$ ( $\varepsilon_{c}$ increases sufficiently much). Since $\alpha$ by assumption increases, the firms' share of $S^{*}$ falls, hence $J^{*}$ falls. But then $p^{*}$ falls as well, and then surely also $(r+s) U^{*}=z+p R^{*}$.. However, as $U^{*}$ is maximized in equilibrium this is a contradiction.

To show the results for $z$ and $c$ we proceed in exactly the same way, and it is therefore sufficient to study the effects of changes keeping $\alpha$ constant. Taking the derivative of $X_{L}$ with respect to $z$ then gives

$$
\frac{\partial X_{L}\left(\varepsilon_{c}\right)}{\partial z}=(r+s) \frac{d U^{*}}{d z}>0 .
$$

Hence, $\varepsilon_{c}$ is increasing in $z$. The argument if $\frac{d \alpha}{d z} \neq 0$ proceeds in exactly the same way as for changes in $\bar{y}$.

Consider changes in $c$. Taking the derivative with respect to $c$ for a given $\alpha$ gives

$$
\frac{\partial X_{L}\left(\varepsilon_{c}\right)}{\partial c}=(r+s) \frac{d U^{*}}{d c}<0
$$

Hence $\varepsilon_{c}$ is decreasing in $c$. The argument if $\frac{d \alpha}{d c} \neq 0$ proceeds in exactly the same way as for changes in $\bar{y}$.

Finally, taking derivative with respect to $A$ for a given $\alpha$ gives

$$
\frac{\partial X_{L}\left(\varepsilon_{c}\right)}{\partial A}=(r+s) \frac{d U^{*}}{d A}>0 .
$$

Hence $\varepsilon_{c}$ is increases in $A$. The argument if $\frac{d \alpha}{d A} \neq 0$ proceeds in exactly the same way as for changes in $\bar{y}$.

\section{Appendix 15: Proof of Lemma 7}

a) Note that $H(\varepsilon)=\widetilde{H}(\varepsilon / k)=\widetilde{H}(\mu)$ and that $h(\varepsilon)=\widetilde{h}(\mu) / k$. Inserting this into (34) gives

$-\left[\bar{y}+k \mu_{c}+\gamma e\left(k \mu_{c}\right)-\psi\left(e\left(k \mu_{c}\right)\right)-(r+s) U^{*}\right]+\alpha k \frac{\left(1-\widetilde{H}\left(\mu_{c}\right)\right)}{\widetilde{h}\left(\mu_{c}\right)} \frac{\psi^{\prime}\left(e\left(k \mu_{c}\right)\right)}{\gamma}=0$.

We proceed in the same way as in Appendix 14. We first want to show that the LHS of (36) increases in $k$ for a given $\alpha$. Denote the first term by FT. 


$$
\frac{\partial F T}{\partial k}=-\left(\mu_{c}+\left(\gamma-\psi^{\prime}(e)\right) \frac{\partial e\left(k \mu_{c}\right)}{\partial k}\right)
$$

From Appendix 12 we know that $b\left(k \mu_{c}\right)$ decreases in $k$ and hence that $e\left(k \mu_{c}\right)$ decreases in $k$. Since $\gamma-\psi^{\prime}(e)>0$, the first term is increasing in $k$ provided that $\mu_{c} \leq 0$.

Denote the second term in the equation by $S T$.

$$
\begin{aligned}
S T & =\alpha k \frac{\left(1-\widetilde{H}\left(\mu_{c}\right)\right)}{\widetilde{h}\left(\mu_{c}\right)} \frac{\psi^{\prime}\left(e\left(k \mu_{c}\right)\right)}{\gamma} \\
& =\alpha k \frac{\left(1-\widetilde{H}\left(\mu_{c}\right)\right)}{\widetilde{h}\left(\mu_{c}\right)} b\left(k \mu_{c}\right) \\
& =\alpha k \frac{\left(1-\widetilde{H}\left(\mu_{c}\right)\right)}{\widetilde{h}\left(\mu_{c}\right)}\left[1-\alpha k \frac{\left(1-\widetilde{H}\left(\mu_{c}\right)\right)}{\widetilde{h}\left(\mu_{c}\right)} \frac{\psi^{\prime \prime}\left(e\left(k \mu_{c}\right)\right)}{\gamma^{2}}\right] \\
& =a_{1} k\left[1-a_{2} k\right] .
\end{aligned}
$$

where $a_{1}=\alpha \frac{\left(1-\widetilde{H}\left(\mu_{c}\right)\right)}{\widetilde{h}\left(\mu_{c}\right)}$ and $a_{2}=\frac{\left(1-\widetilde{H}\left(\mu_{c}\right)\right)}{\widetilde{h}\left(\mu_{c}\right)} \frac{\psi^{\prime \prime}\left(e\left(k \mu_{c}\right)\right)}{\gamma^{2}}$. Now

$$
\frac{\partial S T}{\partial k}=a_{1}\left[1-2 k a_{2}\right]-a_{1} k^{2} \frac{\partial a_{2}}{d k} .
$$

Since $e(k \mu)$ is decreasing in $k$ we know that $\psi^{\prime \prime}\left(e\left(k \mu_{c}\right)\right)$ is decreasing in $k$, and hence that $\frac{\partial a_{2}}{d k}<0$. A sufficient condition for $S T$ being increasing in $k$ is thus that $1-2 a_{2} k>0$, or $a_{2} k<1 / 2$. Since $b\left(k \mu_{c}\right)=1-a_{2} k$ this holds if and only if $b\left(k \mu_{c}\right)>1 / 2$, which is true by assumption.

Suppose then that the equilibrium value of $\alpha$ increases. Then we know from Property P1 in Appendix 5 that this will increase $\varepsilon_{c}$ even further.

Suppose then that $\alpha$ decreases. We want to show that this is incompatible with a decrease in $\varepsilon_{c}$. To this end suppose both $\varepsilon_{c}$ and $\alpha$ decreases. From equation (21) it follows that $b(\varepsilon)$ and thus effort is decreasing in $\alpha$ for all worker types. Using equation (17) the expected rents can be written as

$$
(r+s) R=\int_{\varepsilon_{c}}^{\bar{\varepsilon}} \int_{\varepsilon_{c}}^{\varepsilon} \frac{\psi^{\prime}(e(\varepsilon))}{\gamma} d \varepsilon d H .
$$

It follows that $R$ increases. Consider then the modified Hosios-condition, which we can write as

$$
(1-\alpha) \frac{R^{*}}{S^{*}-R^{*}}=\frac{\beta}{1-\beta} .
$$


An increase in $R$ and a decrease in $\alpha$ is only consistent with the modified Hosios condition if $S^{*}$ increases, in which case $U^{*}$ surely increases (both $R^{*}$ and the job finding rate increases). However, we already know that $U^{*}(k)$ is strictly decreasing in $k$ whenever $\varepsilon_{c}=\underline{\varepsilon}$. Since the equilibrium value $U^{*}$ maximizes $U$ it follows from the envelope theorem that $U$ is decreasing in $k$ whenever $\varepsilon_{c}$ is sufficiently close to $\underline{\varepsilon}$, and we have derived a contradiction.

Result b) We use the same method as above. Consider equation (34). For a given $\alpha$ we know from Appendix 12 and Lemma 6 that an increase in $\gamma$ leads to an increase in $b(\varepsilon)$ for a given $\alpha$, hence the second term of $(34)$ and thus also $\varepsilon_{c}$ increases. If $\alpha$ increase we know from Property P1 that this increases $\varepsilon_{c}$ even further. Hence we have only left to show that $\varepsilon_{c}$ increases even if $\alpha$ falls.

Suppose therefore that $\alpha$ and $\varepsilon_{c}$ fall. Then $b(\varepsilon)$ surely increases, From equation (37) it follows that $R^{*}$ increases.

Consider then the modified Hosios-condition:

$$
(1-\alpha) \frac{R^{*}}{S^{*}-R^{*}}=\frac{\beta}{1-\beta} .
$$

If $\alpha$ falls and $R^{*}$ increases, then surely $J$ and the job finding rate increases as well. Hence the equilibrium value of $U$ increases. However, by assumption $U^{*}$ is constant, and we have derived a contradiction.

\section{References}

Acemoglu, D. and Shimer, R. (1999a), "Efficient Unemployment Insurance", Journal of Political Economy, 107, 893-928.

Acemoglu, D. and Shimer, R. (1999b), "Holdups and Efficiency with Search Frictions", International Economic Review, 40, 827-849.

Baron, D. and Besanko, D. (1984), "Regulation and Information in a Continuing Relationship", Information Economics and Policy, 1, 447-470.

Brugerman, B. and Moscarini, G. (2007), "Rent Rigidity, Asymmetric Information and Labor Market Fluctuations", Department of Economics, Yale University, mimeo.

Danthine, J.-P., and Donaldson, J. B. (1990), "Efficiency Wages and the Business Cycle Puzzle", European Economic Review, 34, 1275-1301. 
Diamond, P.A. (1982), "Wage Determination and Efficiency in Search Equilibrium", Review of Economic Studies, 49, 217-227.

Faig, M. and Jarez, B. (2005), "A Theory of Commerce", Journal of Economic Theory, 122, 60-99.

Fudenberg, D. and Tirole, J. (1991), Game Theory, MIT Press, Cambridge.

Gertler, M., Sala, L., and A. Triari, (2007), "An Estimated Monetary DSGEmodel with Unemployment and Staggered Nominal Wage Bargaining", Boccony University, mimeo

Hall, R. (2004a), "The Labor Market is the Key to Understanding the Business Cycle", Mimeo, Stanford University.

Hall, R. (2004b), "The Amplification of Unemployment through Self-Selection", Mimeo, Stanford University.

Hall, R. (2005), "Employment Fluctuations with Equilibrium Wage Stickiness", American Economic Review, 95, 50-65.

Hosios, A.J. (1990), "On The Efficiency of Matching and Related Models of Search and Unemployment", Review of Economic Studies, 57, 279-298.

Jovanovic, B. (1979), "Job Matching and the Theory of Turnover", Journal of Political Economy, 87, 972-990.

Kennan, J. (2004), "Private Information, Wage Bargaining and Employment Fluctuations", University of Wisconsin-Madison, Mimeo.

Krause, M. U. and Lubik, T. A. (2004), "On-the-Job Search and the Cyclical Dynamics of the Labor Market", Tilburg University, Mimeo.

Laffont, J.J. and Tirole, J (1993), A Theory of Incentives in Procurement and Regulation, MIT Press, Cambridge.

Lazear, Edward P. (2000). "Performance Pay and Productivity", American Economic Review, 90, 1346-1361.

MacLeod, W. Bently and James M. Malcomson (1998), "Motivation and Markets", American Economic Review, 88, 388-411. 
MacLeod, W.B., Malcomson, J.M. and Gomme, P. (1994), "Labor Turnover and the Natural rate of Unemployment: Efficiency Wages versus Frictional Unemployment" Journal of Labor Economics, 12, 276-315.

Menzio, G. (2004), "High-Frequency Wage Rigidity", Northwestern University Mimeo.

Mortensen, D.T (1986), "Job Search and Labour Market Analysis", In O.C. Ashenfelter and R. Layard (eds.),Handbook of Labor Economics Volume 2, Amsterdam, North-Holland, 849-919.

Mortensen, D.T. and Nagypál, É (2006), "More on Unemployment and Vacancy Fluctuations", Northwestern University, Mimeo.

Mortensen, D.T, and Pissarides, C.A. (1999), "New Developments in Models of Search in the Labor Market", in O. Ashenfelter and D. Card (eds.), Handbook of Labor Economics, vol 3b, North-Holland, pp 2567-2627.

Mortensen, D. and Wright, R. (2002), "Competitive Pricing and Efficiency in Search Equilibrium", International Economic Review, 43, 1-20.

Moen, E.R. (1997) "Competitive Search Equilibrium", Journal of Political Economy, 105, 385-411.

Moen, E.R. and Rosén, Å. (2004), "Does Poaching Distort Training?", Review of Economic Studies, 71, 1143-1162.

Moen, E.R. and Rosén, Å. (2006), "Equilibrium Incentive Contracts and Efficiency Wages", Journal of European Economic Association, 4, 1165-1192.

Moen, E.R. and Rosén, Å. (2006), "Incentives in Competitive Search Equilibrium and Wage Rigidity", CEPR Working Paper no 5554.

Nagypál, É. (2004), "Amplification of Productivity Shocks: Why Vacancies Don't Like to Hire the Unemployed?", Northwestern University, Mimeo.

Pissarides, C.A. (1985). "Short-Run Dynamics of Unemployment, Vacancies, and Real Wages", American Economic Review , 75, 675-90.

Pissarides, Christopher A. (2000). Equilibrium Unemployment Theory. MIT press, Cambridge MA. 
Ramey, G and Watson, J. (1997), "Contractual Fragility, Job Destruction, and Business Cycles" Quarterly Journal of Economics, 112, 873-911.

Reiter, M (2007), "Embodied Technical Change and the Fluctuation of Wages and Unemployment". Pompeu Fabra WP no 980.

Rocheteau, G. (2001), "Equilibrium Unemployment and Wage Formation with Matching Frictions and Worker Moral Hazard", Labour Economics, 8, $75-102$.

Rudanko, L (2006), "Labor Market Dynamics under Long Term Wage Contracting and Incomplete Markets", University of Chicago, Mimeo.

Shapiro, C, and Stiglitz, J.E. (1984), "Equilibrium Unemployment as a Worker Discipline Device", American Economic Review, 74, 433-444.

Shimer, R. (2005), "The Cyclical Behavior of Equilibrium Unemployment and Vacancies ", American Economic Review, 95, 25-49.

Shimer, R. and Wright, R. (2004), "Competitive Search Equilibrium with Asymmetric Information", University of Chicago, Mimeo.

Strand, J.(1992), "Business Cycles with Worker Moral Hazard", European Economic Review, 36, 1291-1303.

Weiss, A. W. (1980), "Job Queues and Layoffs in Labor Markets with Flexible Wages", Journal of Political Economy, 88, 525-538. 


\title{
CENTRE FOR ECONOMIC PERFORMANCE Recent Discussion Papers
}

\author{
831 Eran Yashiv \\ U.S. Labor Market Dynamics Revisited \\ 830 Laura Alfaro \\ Andrew Charlton \\ Growth and the Quality of Foreign Direct \\ Investment: Is All FDI Equal? \\ 829 Richard Layard \\ David Clark \\ Martin Knapp \\ Guy Mayraz \\ 828 Emma Tominey \\ 827 Christos Genakos \\ Tommaso Valletti \\ 826 Luis Garicano \\ Paul Heaton \\ 825 Laura Alfaro \\ Andrew Charlton \\ 824 Miklós Koren \\ Silvana Tenreyro \\ Cost-Benefit Analysis of Psychological Therapy \\ Maternal Smoking During Pregnancy and Early \\ Child Outcomes \\ Testing the "Waterbed" Effect in Mobile \\ Telephony \\ Information Technology, Organization, and \\ Productivity in the Public Sector: Evidence from \\ Police Departments \\ Intra-Industry Foreign Direct Investment \\ 823 Régis Barnichon \\ 822 Carlos Thomas \\ 821 Giulia Faggio \\ Kjell G. Salvanes \\ John Van Reenen \\ 820 Luis Araujo \\ Emanuel Ornelas \\ Technological Diversification \\ The Shimer Puzzle and the Correct Identification \\ of Productivity Shocks \\ Search Frictions, Real Rigidities and Inflation \\ Dynamics \\ The Evolution of Inequality in Productivity and \\ Wages: Panel Data Evidence \\ Trust-Based Trade \\ 819 Régis Barnichon \\ Productivity, Aggregate Demand and \\ Unemployment Fluctuations \\ 818 Rachel Griffith \\ Sokbae Lee \\ Is Distance Dying at Last? Falling Home Bias in \\ John Van Reenen \\ 817 Tsutomu Miyagawa \\ YoungGak Kim \\ Fixed Effects Models of Patent Citations \\ Measuring Organization Capital in Japan: An \\ Empirical Assessment Using Firm-Level Data \\ 816 Andreas Georgiadis \\ Alan Manning \\ Spend It Like Beckham? Inequality and \\ Redistribution in the UK, 1983-2004
}




\begin{tabular}{|c|c|c|}
\hline 815 & $\begin{array}{l}\text { Guy Michaels } \\
\text { Xiaojia Zhi }\end{array}$ & Freedom Fries \\
\hline 814 & Ralph Ossa & $\begin{array}{l}\text { Trade Liberalization, Outsourcing, and Firm } \\
\text { Productivity }\end{array}$ \\
\hline 813 & $\begin{array}{l}\text { Karsten Kohn } \\
\text { Alexander C. Lembcke }\end{array}$ & $\begin{array}{l}\text { Wage Distributions by Bargaining Regime: Linked } \\
\text { Employer-Employee Data Evidence from Germany }\end{array}$ \\
\hline 812 & $\begin{array}{l}\text { Yannis M. Ioannides } \\
\text { Henry G. Overman } \\
\text { Esteban Rossi-Hansberg } \\
\text { Kurt Schmidheiny }\end{array}$ & $\begin{array}{l}\text { The Effect of Information and Communication } \\
\text { Technologies on Urban Structure }\end{array}$ \\
\hline 811 & Guy Michaels & $\begin{array}{l}\text { The Division of Labor, Coordination, and the } \\
\text { Demand for Information Processing }\end{array}$ \\
\hline 810 & $\begin{array}{l}\text { Maia Güell } \\
\text { Jose V. Rodriguez Mora } \\
\text { Chris Telmer }\end{array}$ & $\begin{array}{l}\text { Intergenerational Mobility and the Informative } \\
\text { Content of Surnames }\end{array}$ \\
\hline 809 & $\begin{array}{l}\text { Stephen J. Redding } \\
\text { Daniel M. Sturm } \\
\text { Nikolaus Wolf }\end{array}$ & $\begin{array}{l}\text { History and Industry Location: Evidence from } \\
\text { German Airports }\end{array}$ \\
\hline 808 & Anna Lipinska & $\begin{array}{l}\text { The Maastricht Convergence Criteria and Optimal } \\
\text { Monetary Policy for the EMU Accession Countries }\end{array}$ \\
\hline 807 & Eran Yashiv & The Beveridge Curve \\
\hline 806 & $\begin{array}{l}\text { Ghazala Azmat } \\
\text { Alan Manning } \\
\text { John Van Reenen }\end{array}$ & $\begin{array}{l}\text { Privatization, Entry Regulation and the Decline of } \\
\text { Labor's Share of GDP: A Cross-Country Analysis } \\
\text { of the Network Industries }\end{array}$ \\
\hline 805 & $\begin{array}{l}\text { Henry G. Overman } \\
\text { Patricia Rice } \\
\text { Anthony J. Venables }\end{array}$ & Economic Linkages Across Space \\
\hline 804 & Benjamin Aleman-Castilla & $\begin{array}{l}\text { The Returns to Temporary Migration to the United } \\
\text { States: Evidence from the Mexican Urban } \\
\text { Employment Survey }\end{array}$ \\
\hline 803 & Eran Yashiv & Labor Search and Matching in Macroeconomics \\
\hline 802 & Nicholas Oulton & $\begin{array}{l}\text { Jeremy Greenwood and Per Krusell, “Growth } \\
\text { Accounting with Investment-Specific } \\
\text { Technological Progress: A Discussion of Two } \\
\text { Approaches” A Rejoinder }\end{array}$ \\
\hline 801 & $\begin{array}{l}\text { Mirabelle Muûls } \\
\text { Mauro Pisu }\end{array}$ & $\begin{array}{l}\text { Imports and Exports at the Level of the Firm: } \\
\text { Evidence from Belgium }\end{array}$ \\
\hline
\end{tabular}

